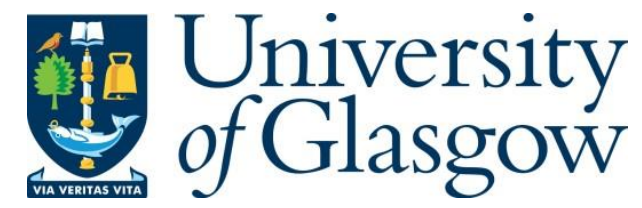

Byrne, J., Korobilis, D. and Ribeiro, P. J. (2016) Exchange rate predictability in a changing world. Journal of International Money and Finance, 62, pp. 1-24. (doi:10.1016/j.jimonfin.2015.12.001)

This is the author's final accepted version.

There may be differences between this version and the published version. You are advised to consult the publisher's version if you wish to cite from it.

http://eprints.gla.ac.uk/113136/

Deposited on: 7 December 2015

Enlighten - Research publications by members of the University of Glasgow http://eprints.gla.ac.uk 


\title{
Exchange Rate Predictability in a Changing World
}

\author{
Joseph P. Byrne ${ }^{\mathrm{a}}$, Dimitris Korobilis ${ }^{\mathrm{b}}$, Pinho J. Ribeiro ${ }^{\mathrm{b}, *}$ \\ ${ }^{a}$ Heriot-Watt University, School of Management and Languages, Edinburgh, EH14 4AS, UK. \\ ${ }^{b}$ University of Glasgow, Adam Smith Business School, Glasgow, G12 8RT, UK.
}

\begin{abstract}
An expanding literature articulates the view that Taylor rules are helpful in predicting exchange rates. In a changing world however, Taylor rule parameters may be subject to structural instabilities, for example in the aftermath of the Global Financial Crisis. This paper forecasts exchange rates using Taylor rules with Time-Varying Parameters (TVP) estimated by Bayesian methods. Focusing on the data from the crisis, we improve upon the random walk for at least half, and for as many as seven out of 10, of the currencies considered. Results are stronger when we allow the TVP of the Taylor rules to differ between countries.
\end{abstract}

Keywords:

Exchange Rate Forecasting, Taylor Rules, Time-Varying Parameters, Bayesian Methods JEL Codes:

C53, E52, F31, F37, G17

\section{Introduction}

Academics and market practitioners have both sought to predict exchange rate fluctuations. A long held view, initiated by Meese and Rogoff (1983), proposed that forecasts based upon macroeconomic fundamentals could not improve upon a random walk benchmark. Rossi (2013) provides a survey of the subsequent literature that examined the predictive content of macroeconomic fundamentals, using theoretical and empirical innovations. Theoretical improvements have included studying the behavior of exchange rates in present-value models (Engel and West, 2005). Separately, empirical advances have

${ }^{*}$ Corresponding author. University of Glasgow, Adam Smith Building, Room 512, Glasgow G12 8RT, UK. Tel: +44(0)1413308506

Email address: p.ribeiro.1@research.gla.ac.uk (Pinho J. Ribeiro) 
included nonlinear methods, such as the exponential smooth transition auto-regressive model of Kilian and Taylor (2003) and time-varying parameter models (e.g., Rossi, 2006; Wolff, 1987). ${ }^{1}$ This paper seeks to combine these theoretical and empirical innovations in predicting exchange rates, in a changing world.

Engel and West (2005) and Engel et al. (2008) illustrate that models that can be cast in the standard present-value asset pricing framework imply that exchange rates are approximately random walks. This result holds under the assumptions of non-stationary fundamentals and a near unity discount factor. However, Engel and West (2004) present evidence that even when the discount factor is near one, a class of models based on observable fundamentals can still account for a fairly large fraction of the variance in exchange rates. An example in this class includes structural exchange rate models in which monetary policy follows the Taylor (1993) rule. Engel et al. (2008), Molodtsova and Papell (2009), and Rossi (2013) find that empirical exchange rate models conditioned on information sets from Taylor rules outperform the random walk benchmark in out-ofsample forecasting, particularly at short-horizons.

Despite the optimism instilled by this emerging research one area remains unresolved. Exchange rate forecasting models are subject to parameter instability. Rossi and Sekhposyan (2011), for example, detect significant instabilities in models that employ classic and Taylor rule fundamentals. In their study, Meese and Rogoff (1983) had already conjectured that parameter instability may rationalize the poor forecasting performance of exchange rate models. To address the issue, several researchers have attempted to account for time-variation in parameters when forecasting exchange rates. Nonetheless, as Rossi (2013) and Rogoff and Stavrakeva (2008) point out, the problem has not yet been fully resolved. In fact, Rossi (2013) questions whether instabilities can be exploited to improve exchange rate forecasts.

In this paper we revisit the issue of forecasting exchange rates with time-varying parameter models. In a major break with the earlier literature, our starting point is that

\footnotetext{
${ }^{1}$ See Rossi (2013) for a review of other empirical approaches.
} 
macroeconomic conditions and policy actions evolve, often suddenly. ${ }^{2}$ Following this idea, our modelling strategy allows for fast changing dynamics in the process that determine macroeconomic fundamentals, which in turn influence the path of the exchange rate. Only after these dynamics have been accounted for, we then proceed and allow for time-variation in parameters when predicting exchange rates. To help achieve efficiency when estimating the parameters we use information in the likelihood based upon Bayesian methods. As Kim and Nelson (1999) refer, Bayesian methods treat all the unknown parameters in the system as jointly distributed random variables, such that each parameter estimate reflects uncertainty about the other parameters. In contrast, estimates based on classical maximum likelihood are prone to errors, since a large number of likelihood functions have to be evaluated. Therefore, unlike the previous literature, we do not rely on classical maximum likelihood methods (as in Rossi, 2006) or calibration (e.g. Wolff, 1987; Bacchetta et al., 2009), which can also be subjective and may give less accurate parameter estimates and inferior forecasting performance. ${ }^{3}$

It is straightforward to recognize the relevance of allowing for time-evolving macroeconomic fundamentals. If the process underlying macroeconomic fundamentals changes rapidly over time their predictive content may depend upon statistically modelling it. And empirically, there is widespread evidence pointing out to time-evolving dynamics in fundamentals. In the context of fundamentals determined by Taylor rules, Boivin (2006), Kim and Nelson (2006), and Cogley et al. (2010) find that the U.S. Federal Reserve conduct of monetary policy is better characterized by a changing-coefficients Taylor rule. Trecroci and Vassalli (2010) present similar findings for the U.S., U.K., Germany, France and Italy.

There is also a large literature documenting time-evolving relationships between fundamentals and exchange rates. Bacchetta and van Wincoop (2004), for instance, explain

\footnotetext{
${ }^{2}$ See for example, Stock and Watson (1996) for evidence on structural instabilities in macroeconomic time series in general.

${ }^{3}$ Giannone (2009) provides a helpful critique of the results based on Bacchetta's et al.(2009) calibration and shows how using the full maximum likelihood setup in a Bayesian framework is important in accounting for instabilities. Balke et al. (2013) also use Bayesian methods and focus upon modelling exchange rates in-sample with monetary fundamentals.
} 
this relationship on the basis of a scapegoat theory. Traders in foreign exchange markets seek explanations for fluctuations in the exchange rate, such that even when an unobservable variable is the cause of the fluctuation, they explain it on the basis of something they can observe, the macro variable. The macro variable is therefore a scapegoat, which in turn influences trading behavior and the exchange rate. Over time, fluctuations in exchange rates are then explained by time-varying weights attributed to scapegoat variables. In a recent application, Balke et al. (2013) and Park and Park (2013) show that allowing for such dynamics in the monetary model improves in-sample fit and out-of sample predictive power for exchange rates.

Putting together these observations, we advance a framework where fundamentals themselves and their interaction with exchange rates change over time. In particular, we estimate time-varying parameter Taylor rules and examine their predictive content in a setting that allows for the parameters of the forecasting regression to change over time. ${ }^{4}$ If we further consider the recent events in the world economy, our approach is also timely and topical. Analyzing exchange rates behavior for the period before and after the 2008 turmoil, Mumtaz and Sunder-Plassmann (2013) observe a markedly high volatility in recent years. Similarly, Taylor (2009) argues that prior to the Global Financial Crisis the U.S. Federal Reserve conduct of monetary policy was characterized by a non-linear Taylor rule. After the Crisis, central banks around the world have adopted unconventional monetary policy when confronted with the zero lower bound constraint on nominal interest rates. Furthermore, there has been a considerable heterogeneity in country-specific frictions, which required bespoke policy measures (Draghi, 2014). All these developments suggest that the constant-parameter forecasting approach used in studies focusing in the samples before the recent turmoil may be ill-suited to capture the dynamics in the recent turbulent times. In this sense, our study extends the results in these papers, including Engel et al. (2008), Engel and West (2005, 2006), Molodtsova and Papell (2009), Rogoff and Stavrakeva (2008). ${ }^{5}$

\footnotetext{
${ }^{4}$ Although in principle forecasting in a rolling regression scheme allows for parameters to change over time, a TVP model allows for instabilities to be updated systematically and more flexibly.

${ }^{5}$ Focusing in a sample before the 2008 financial crisis, Mark (2009) uses a non-linear modelling
} 
In particular, this paper's dataset consists of quarterly exchange rates from 1973Q1 to 2013Q1, on up to 17 OECD countries relative to the U.S. dollar. We calculate Theil's U-statistic from Root Mean Squared Forecast Error (RMSFE) recursively out-of-sample, whilst focusing in three forecast samples and four quarterly forecasting horizons $(h=$ $1,4,8,12)$. We assess the significance of the differences in the forecasts using the Diebold and Mariano (1995) and West (1996) tests, with bootstrapped critical values. We further inspect statistical significance using the typical aymptotic Clark and West (2006) test.

To preview our results, allowing for time-varying Taylor rules improves upon the driftless random walk at horizons beyond 1-quarter. In fact, for periods during and after the Global Financial Crisis, our approach yields a lower RMSFE than the benchmark for at least half of the currencies, and for as many as seven out of 10 currencies. When we examine the performance of a Fixed-Effect panel model, as a variant of models with constantparameters, we find improvement over the RW mostly in the early, but marginally less in the late parts of our dataset. Our TVP regressions also perform only marginally better than standard linear regressions employed in a rolling window forecasting approach.

The rest of the paper proceeds as follows. The next section sets out the Time-Varying Parameter regression we consider. Section 3 discusses the choice of fundamentals, and Section 4 covers data description and the mechanics of our forecasting exercise. The main empirical results are reported in Section 5. Section 6 summarizes the findings and deals with robustness checks. We conclude in Section 7.

\section{The time-varying parameter regression}

A common practice in forecasting exchange rates is to model the change in the exchange rate as a function of its deviations from its fundamental implied value. As put forward by Mark (1995), this accords with the notion that exchange rates frequently deviate from the level implied by fundamentals, particularly in the short-run. More precisely,

strategy. He employs a Vector Autoregressive model and least-squares learning techniques to update Taylor rules estimates, inflation, and output gap which are then used to compute the exchange rate value. Using in-sample evidence, he finds that allowing for time-variation in parameters is relevant to account for the volatility of the Deutschemark and the Euro, relative to the U.S. dollar. Our approach differs from Mark (2009) in that we focus upon out-of-sample predictability of non-linear Taylor rules. 
define $s_{t+h}-s_{t} \equiv \Delta s_{t+h}$ as the $h$-step-ahead change in the log of exchange rate, and $\Omega_{t}$ a set of exchange rate fundamentals. Then,

$$
\begin{aligned}
\Delta s_{t+h} & =\beta_{0 t}+\beta_{1 t} z_{t}+\varepsilon_{t+h}, \quad \varepsilon_{t+h} \sim N(0, R) \\
z_{t} & =\Omega_{t}-s_{t} .
\end{aligned}
$$

As Eq. (2) suggests, $\Omega_{t}$ signals the exchange rate's fundamental value, hence $z_{t}$ is the deviation from the fundamental's implied level. When the spot exchange rate is lower than the level implied by the fundamentals, i.e., $s_{t}<\Omega_{t}$, then the spot rate is expected to increase.

In Eq. (1) the time-subscripts $t$ attached to the coefficients $\beta_{t}=\left[\beta_{0 t}, \beta_{1 t}\right]$ characterizes them as changing over time. The exact coefficient's law of motion is inspired, among others, by Stock and Watson (1996), Rossi (2006), and Boivin (2006). We assume a Random Walk Time-Varying Parameter (RW-TVP) process:

$$
\beta_{t}=\beta_{t-1}+v_{t}
$$

where the error term $\left(v_{t}\right)$ is assumed homoscedastic, uncorrelated with $\varepsilon_{t+h}$ in Eq. (1), and with a diagonal covariance matrix $Q$. Equations (1) and (3) make up a state-space model, where (1) is the measurement equation and (3) the transition equation.

This paper uses Bayesian methods to estimate the parameters of the state-space model. Using the Kalman filter with maximum likelihood is another potential method, but as Kim and Nelson (1999, Ch. 8) note, the evaluation of a large number of likelihood functions may undermine the estimates. With the method of maximum likelihood there is potential for accumulation of errors, as estimation of the state variables is conditional upon maximum likelihood estimates of the other parameters of the system. There is also the issue of identifying objective priors to initialize the Kalman filter. The solution to this latter issue involves setting diffuse priors or using a training sample, but solving the problem of obtaining efficient parameter estimates is more challenging. Bayesian methods, in contrast, treat all the unknown parameters in the system as jointly distributed 
random variables, such that the estimate of each of them reflects uncertainty about the others (see Kim and Nelson, 1999 for further discussion).

In particular, we employ the Carter and Kohn (1994) algorithm and the Gibbs sampler to simulate draws from the parameters' posterior distribution. The Gibbs sampler, which falls in the class of Markov Chain Monte Carlo (MCMC) methods, is a numerical method that uses draws from conditional distributions to approximate joint and marginal distributions. To implement the method we need to (i) elicit priors for the unknown parameters, (ii) specify the form of their posterior conditional distributions, and finally (iii) draw samples from these posterior distributions.

We use pre-sample information to parameterize the prior distributions. We do so largely because we are comparing the forecasting performance of several models, at a number of forecast samples and horizons. By setting priors based on a training sample we ensure that all the models are based on the same prior elicitation setting, and therefore their performance is not influenced by the model's particular prior parameterization choice. This approach also provides natural shrinkage based on evidence in the likelihood, which in turn ensures that TVP estimates will be more accurate, with smaller variance, resulting in a sharper inference and potentially more precise forecasts. The remainder of the details about priors' elicitation and the steps of the algorithm are provided in Appendix A.

\section{Taylor rule fundamentals}

Having defined the form and the method to estimate the parameters of our main forecasting regression an additional modelling issue relates to the exact specification of the fundamental information contained in $\Omega_{t}$. In this regard, our approach is consistent with models that relate the exchange rate to macroeconomic variables within the asset pricing setting (Engel and West, 2005). In this setting, the exchange rate is expressed as the present-value of a linear combination of economic fundamentals and unexpected shocks. Assuming rational expectations and a random walk process for the fundamentals, the framework implies that the spot exchange rate is determined by current observable 
fundamentals and unobservable noise.

We focus primarily on observable fundamentals derived from the Taylor (1993) rule. According to this rule, the monetary authority should set the target for the policy interest rate considering inflation and its deviation from some target, output deviation from potential, and the equilibrium real interest rate. Then, it follows that the authority increases the policy rate when inflation is above the target and/or output is above its potential level.

An emerging research considers the implications of this policy setting for exchange rates, including Engel and West (2005), Engel et al. (2008), Mark (2009), and Molodtsova and Papell $(2009,2013)$. The premise is that the home and the foreign central banks conduct monetary policy following a Taylor rule. In line with this framework, the foreign monetary authority, such as the U.S. in our empirical section, is concerned with inflation and output deviations from their target values. In addition to these targets, Engel and West (2005) assume that the home country also targets the real exchange rate. It is equally common to consider that central banks adjust the actual interest rate to eliminate a fraction of the gap between the current interest rate target and its recent past level, known as interest rate smoothing. By subtracting the foreign Taylor rule from the home, the following interest rate differentials equation is obtained:

$$
\begin{aligned}
i_{t}-i_{t}^{*} & =\phi_{0}+\phi_{1} \pi_{t}-\phi_{1}^{*} \pi_{t}^{*}+\phi_{2} \bar{y}_{t}-\phi_{2}^{*} \bar{y}_{t}^{*} \\
& +\phi_{3} q_{t}+\phi_{4} i_{t-1}-\phi_{4}^{*} i_{t-1}^{*}+\mu_{t},
\end{aligned}
$$

where $i_{t}$ is the short-term nominal interest rate set by the central bank, asterisks indicate foreign (i.e, U.S.) variables, $\pi_{t}$ is inflation, $\bar{y}_{t}$ denotes the output gap, $q_{t}$ is the real exchange rate defined as $q_{t}=s_{t}+p_{t}^{*}-p_{t}, p_{t}$ is the $\log$ of the price level, $\phi_{l}$ for $l=1, \ldots, 4$ are regression coefficients, and $\mu_{t}$ is an error term which is assumed to be Gaussian. ${ }^{6}$

The link from monetary policy actions to exchange rates occurs through Uncovered Interest Rate Parity (UIRP) under distortions in beliefs about future interest rates as

\footnotetext{
${ }^{6}$ For a detailed derivation of equation (4) see Section 1 of the Online Appendix.
} 
in Gourinchas and Tornell (2004). Molodtsova and Papell (2009) discuss at length such mechanisms. Under UIRP and rational expectations, any circumstance that causes the home (foreign) central bank to increase its policy rate relative to the foreign (home), will lead to an expected depreciation of its currency. However, the empirical evidence frequently rejects the UIRP condition and this is known as the forward premium puzzle (Engel, 1996). In Gourinchas and Tornell (2004) the puzzle arises due to a systematic distortion in investors' beliefs about the interest rate path. They show theoretically and empirically that under these distorted beliefs, an increase in the home country's interest rate can lead to a consequent currency appreciation instead of a depreciation. ${ }^{7}$ Assuming this evidence, an increase in the home country's inflation above the target, a rise in the output gap, or a deviation of the real exchange from the target will trigger an increase in its interest rate, cause appreciation, and a forecast of additional appreciation.

Using Eq. (4) to estimate Taylor rule fundamentals is valid when parameters are constant over time. In a dynamic world, Taylor rule parameters may be subject to structural instabilities. In this context, rather than estimating or assuming Taylor rules fundamentals from models with constant or calibrated parameters, we allow for the possibility of monetary policies that respond to macroeconomic conditions in a time-varying fashion. Accordingly, we estimate fundamentals from Taylor rules using the following TVP regression:

$$
\begin{aligned}
i_{t}-i_{t}^{*} & =\phi_{0 t}+\phi_{1 t} \pi_{t}-\phi_{1 t}^{*} \pi_{t}^{*}+\phi_{2 t} \bar{y}_{t}-\phi_{2 t}^{*} \bar{y}_{t}^{*} \\
& +\phi_{3 t} q_{t}+\phi_{4 t} i_{t-1}-\phi_{4 t}^{*} i_{t-1}^{*}+\mu_{t},
\end{aligned}
$$

from which we compute the fundamentals as:

$$
\begin{aligned}
\Omega_{t} & \equiv \widehat{\phi}_{0 t}+\widehat{\phi}_{1 t} \pi_{t}-\widehat{\phi}_{1 t}^{*} \pi_{t}^{*}+\widehat{\phi}_{2 t} \bar{y}_{t}-\widehat{\phi}_{2 t}^{*} \bar{y}_{t}^{*} \\
& +\widehat{\phi}_{3 t} q_{t}+\widehat{\phi}_{4 t} i_{t-1}-\widehat{\phi}_{4 t}^{*} i_{t-1}^{*}+s_{t},
\end{aligned}
$$

\footnotetext{
${ }^{7}$ See Gourinchas and Tornell (2004) for the exact mechanics.
} 
where $\widehat{\phi}_{l t}$, for $l=1, \ldots, 4$, denotes the time $t$ coefficient's estimate. Note that the model in Eq. (5) is identical to Eq. (4), except for the time-varying coefficients. Thus, the information set from Taylor rules and the exchange rate forecasts are generated from TVP regressions.

The exact form of the Taylor rule and hence of Eq. (5) varies depending upon several assumptions. In all Taylor rules, the equilibrium real interest rate and the inflation target of the home and foreign country are assumed identical. This corresponds to setting $\phi_{0 t}=0$ in Eq. (5). ${ }^{8}$ In addition, all specifications are asymmetric, implying that the home country also targets the real exchange rate.

Our models differ in some ways too, see Table 1. The first Taylor rule specification, which we denote TRon, assumes homogeneous coefficients and no interest rate smoothing. This restricts the coefficients on inflation $\left(\phi_{1 t}=\phi_{1 t}^{*}\right)$ and the output gap $\left(\phi_{2 t}=\phi_{2 t}^{*}\right)$ of the home and foreign country rules. Engel and West (2006) find that it is reasonable to assume parameter homogeneity across countries. In addition, central banks do not smooth interest rates $\left(\phi_{4 t}=\phi_{4 t}^{*}=0\right)$. The assumption of no interest rate smoothing is in line with Engel and West (2005) and several models in Molodtsova and Papell (2009).

A second Taylor rule specification is similar to the above except that it includes lagged interest rates. This is an asymmetric rule with homogeneous coefficients and interest rate smoothing (TRos). Since the assumption of coefficients' homogeneity between countries is maintained, then $\phi_{4 t}=\phi_{4 t}^{*}$ in Eq. (5). The inclusion of lagged interest rates implies that central banks limit interest rate variability, in the spirit of Engel et al. (2008), Mark (2009), and Molodtsova and Papell (2009).

The third variant relaxes the assumption of homogeneous coefficients across countries, and central banks do not smooth interest rates. In terms of Eq. (5), $\phi_{4 t}=\phi_{4 t}^{*}=0$ and is an asymmetric rule with heterogeneous coefficients and no interest rate smoothing (TRen). Molodtsova and Papell (2009) find that models of this type exhibit a strong forecasting performance.

\footnotetext{
${ }^{8}$ This is a typical assumption in this literature, see e.g., Engel and West (2005). As Molodtsova and Papell (2013) also note, whether to include a constant that captures differences in the equilibrium real interest rate and inflation target is irrelevant, because the forecasting regression includes a constant.
} 


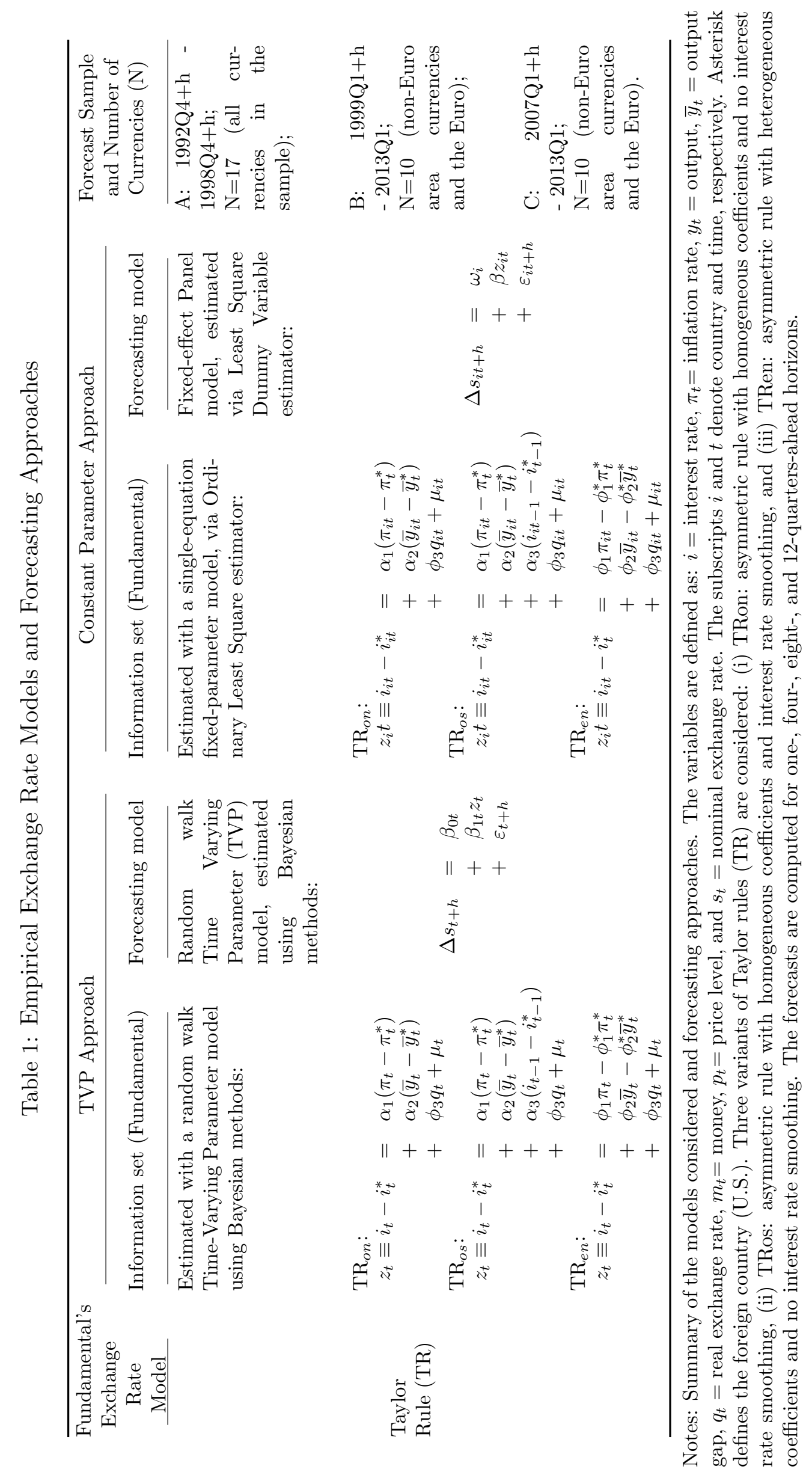


To estimate each of these variants we set up a state-space model as in Section 2, but here the measurement equation takes the form of Eq. (5) and the transition process also follows a random walk, i.e., as in Eq. (3) but with $\beta_{t}$ replaced by $\phi_{t}$. We equally use Bayesian estimation methods, and details about priors' elicitation, posterior distributions, and the sampling algorithm are provided in Appendix A. Like in the forecasting regression, we rely on data-based information to parameterize priors and to define initial conditions.

Apart from our main forecasting regression which allows the coefficients to vary over time we also forecast with constant coefficients models. Precisely, we use a Fixed-Effect (FE) panel regression given the results in Engel et al. (2008) and Ince (2014), regarding the superior forecasting ability of panel data methods relative to single-equation methods. In any event, in a robustness analysis we verify whether using a linear regression alters the results. In both cases, the information set from Taylor rules is obtained by estimating via OLS a single-equation constant parameter model akin to Eq. (4).

\section{Data and forecasting mechanics}

\subsection{Data}

We use quarterly data spanning 1973Q1 - 2013Q1. Exchange-rates are end-of-quarter values of the national currencies relative to the U.S. dollar for the following OECD countries: Australia, Austria, Belgium, Canada, Denmark, Finland, France, Germany, Japan, Italy, Korea, Netherlands, Norway, Spain, Sweden, Switzerland, and the United Kingdom. The main source is the IMF's International Financial Statistics database. Some of the countries in our sample period moved from their national currencies to the Euro. To generate the exchange rate series for these countries the irrevocable conversion factors adopted by each country on the $1^{\text {st }}$ of January 1999 were employed, in the spirit of Engel et al. (2015).

To estimate Taylor rules we need the short-run nominal interest rates set by central banks, inflation rates, and the output gap or the unemployment gap. ${ }^{9}$ We use the cen-

\footnotetext{
${ }^{9}$ In estimating Taylor rules and due to possible endogeneity issues, several authors emphasize the
} 
tral bank's policy rate when available for the entire sample period, or alternatively the discount rate or the money market rate. The proxy for quarterly output is industrial production (IP) in the last month of the quarter. The output gap is obtained by applying the Hodrick and Prescott (1997) filter recursively to the IP series. To correct for the uncertainty about these estimates at the sample end-points we follow Watson's (2007) methodology. We estimate bivariate $\operatorname{VAR}(\ell)$ models that include the first difference of inflation and the change in the log IP, with $\ell$ determined by Akaike Information Criterion. These models are then used to forecast and backcast three years of quarterly data-points of IP, and the HP filter is applied to the resulting extended series. ${ }^{10}$ The price level consists of the consumer price index (CPI) and the inflation rate is defined as the (log) CPI quarterly change. The data on money supply, IP, unemployment rate, and CPI were seasonally adjusted by taking the mean over four quarters following Engel et al. (2015).

\subsection{Forecast implementation}

Our forecasting exercise covers short and long horizons. Following Engel et al. (2008, 2015), we use a direct rather than an iterative method to forecast the $h$-quarter-ahead change in the exchange rates for $h=1,4,8,12$. The benchmark model is the driftless random walk. Since the seminal contribution by Meese and Rogoff (1983) it has been found that it is challenging to improve upon this benchmark (see Rossi, 2013 for a survey of the evidence to date).

The models' parameters are recursively re-estimated in an expanding window and using lagged fundamentals. For concreteness, let $T+h=R+P$ be the sample size comprising a proportion of $R$ observations for in-sample estimation, and $P$ for prediction

timing of the data employed. The discussion centres on the idea that Taylor rules are forward-looking, and hence ex-post data might reflect policy actions taken in the past. Kim and Nelson (2006) note two approaches that can be employed to account for this. The first comprises using historical realtime forecasts that were available to policy-makers. The second consists in using ex-post data to directly model the policy-makers' expectations. Since historical real-time forecasts are unavailable for our sample of countries, we follow Molodtsova and Papell's (2009) approach, and use data that were observed (as opposed to the real-time forecasts) at time $\mathrm{t}$, while forecasting $\mathrm{t}+\mathrm{h}$ period.

${ }^{10}$ We have also experimented with estimating an $\operatorname{AR}(\ell)$ model for $\Delta \ln \left(I P_{t}\right)$ instead of a $\operatorname{VAR}(\ell)$ model. The resulting output gap series were similar to the those based on the VAR forecasts, suggesting small differences in the forecast precision between the two models. Note that we use the standard smoothing parameter for quarterly data (i.e., 1600). 
at $h$-step-forecasting horizon. Hence, $T+h$ constitutes the total number of observations after discarding data-points used to parameterize priors for the TVP models. We first use $R$ observations to compute the information set and to generate the parameters of the exchange rate forecasting regression. With these parameters we generate the first $h$-step-ahead forecast and compute the forecast error. We then add one observation at a time to the end of the in-sample period and repeat the same procedure until all $P$ observations are used. This suggests that allowing for time-variation in parameters in a recursive forecasting approach ultimately results in two potential sources of variation in parameters. The first is due to our recursive algorithm when computing the optimal parameter at each time of the in-sample period. The second source arises from extending the sample as observations are added to end of the in-sample period (recursions). Our TVP forecasting approach is, therefore, highly flexible. ${ }^{11}$

We examine the forecasting performance of our models in three sub-samples. The first out-of-sample forecasts are for the period 1992Q4+h-1998Q4+h. In this sample, forecasts for all the 17 countries' currencies exchange rates are generated. Since towards the end of the sample the realization occurs during the Euro area, we use the rescaled exchange rate to compare against the forecast. A second forecast sample covers the post-Euro period: 1999Q1+h - 2013Q1. In this case we compute the forecast of the Euro currency as an average of the forecasts of the Euro-area countries in our sample. The forecast error is constructed as the difference between each of the country's realized value and the computed average. We therefore generate forecasts for the nine non-Euro area countries plus the Euro. These procedures draw from Engel et al. (2015). The last out-of-sample forecast period begins just before the recent financial turmoil and extends to the end of the sample, i.e., 2007Q1+h - 2013Q1. Considering this window is particularly important, given the substantial instabilities that characterized the period

\footnotetext{
${ }^{11}$ Note that $R$ corresponds to 1979Q1 - 1994Q4 for the first forecast sample; 1979Q1 - 1998Q4 for the second forecast sample; and 1979Q1 - 2006Q4 for the last forecast sample, see Table 1. To illustrate the mechanics described in the paragraph, consider the case of $h=4$ and for the first forecast sample. We use $t=1979 \mathrm{Q} 1-1994 \mathrm{Q} 4$ to estimate regressions of the form: $s_{t+4}-s_{t}=\beta_{0 t}+\beta_{1 t} z_{t}+\varepsilon_{t+4}$. Using the parameters estimated from this regression, we use data from 1995Q4 to forecast the $h=4$ change in the exchange rate: $s_{1996 Q 4}-s_{1995 Q 4}=\widehat{\beta}_{0 t}+\widehat{\beta}_{1 t} z_{1995 Q 4}$. One observation is then added to the end of sample and the procedure is repeated.
} 
with consequences for the monetary policy reaction functions and the variance of the exchange rate. In this sample we also compute forecasts for 10 currencies, following the procedure just described.

\subsection{Forecast evaluation}

We mainly employ the sample RMSFE to compare the out-of-sample forecasting performance of our models. We compute the ratio of the RMSFE of the fundamentals-based exchange rate model relative to RMSFE of the driftless random walk, known as the Theil's U-statistic. Models that perform better than the benchmark have a Theil's U below one. ${ }^{12}$

To evaluate the significance of the differences in the forecasts of competing models, typically, the tests proposed by Diebold and Mariano (1995), West (1996) (hereafter DMW), and Clark and West (2006) (hereafter CW) are employed. However, Clark and West (2006) show that when comparing nested models, the DMW test is undersized, and hence the RMSFE differential should be adjusted by a term that accounts for the bias introduced by the larger model. On the other hand, Rogoff and Stavrakeva (2008) make the case for using the bootstrapped DMW test rather than the $\mathrm{CW}$ test, arguing that the latter does not always test for minimum mean square forecast error. They also recall the applicability of the asymptotics of the CW test when forecasting in a rolling, rather than recursive framework. For these reasons, we follow their recommendation and use a semi-parametric bootstrap to construct $p$-values of the DMW test-statistic in the spirit of Kilian (1999) and Rogoff and Stavrakeva (2008). We apply this bootstrap to primarily evaluate the forecasts from the FE panel regression and from an additional OLS regression that we consider in a robustness analysis.

To evaluate the forecasts from the TVP regressions we employ a procedure equivalent to the bootstrap above, but relying on output from our MCMC method, see Korobilis (2013). Since for each draw in our MCMC algorithm we can compute the DMW-test, we can as well obtain the empirical distribution of the test from which we can calculate the

\footnotetext{
${ }^{12}$ By fundamentals-based exchange rate model we refer to any of the models given in Table 1.
} 
critical values. We proceed in this fashion due to the high computational requirements to implement the bootstrap referred above with MCMC methods. Moreover, to check how inference based on boostrapped critical values alters conclusions drawn from commonly used procedures, we further examine statistical significance based on the aymptotic CW test. As well, using the CW test allows us to establish parallelism of our results with the majority of exchange rate studies. For details on our bootstrap procedures, see Section 3 of the Online Appendix. ${ }^{13}$

\section{Empirical results}

Tables 2, 3, and 4 show results from the TVP forecasting regression and the FE panel regression. Each table corresponds to a different forecasting sample and the entries are the relative RMSFE, or simply the U-statistics. Statistically significant differences in the RMSFE based on our bootstrapped critical values are marked with asterisks, whilst significance based on the asymptotic CW test is symbolized by the plus sign.

Focusing first on the TVP regression, we find improvements upon the RW in the first and most notably, the last forecast sample. In the first forecast sample in Table 2, the TVP regression conditioned on Taylor rules with homogenous coefficients and no interest rate smoothing (TRon) yields a lower RMSFE than the RW for 11 out of 17 currencies at $h=8$, and nine out of 17 at $h=12$. However, at shorter horizons its performance deteriorates when conditioned on any of the Taylor rule specifications. This is the case at $h=1$ and 4 quarters, where the RW benchmark forecasts better for over half of the currencies in all cases and regardless of the Taylor rule specification. In contrast, in the last forecast sample in Table 4, the TVP regression with fundamentals from any of the Taylor rule specifications beats the RW for at least half of the currencies for horizons beyond 1-quarter. The specification with heterogeneous coefficients and no interest rate smoothing, denoted TRen, exhibits the strongest performance; it delivers a lower RMSFE than the RW for seven out of 10 currencies at $h=4$, and six out of 10 at $h=8,12$.

\footnotetext{
${ }^{13}$ In computing the sample long-run variance for the DMW (CW) test, we use the Newey and West's (1987) HAC standard errors with a lag truncation parameter of $\operatorname{int}\left\{\right.$ Sample $\left.^{0.25}\right\}$, as in Rossi (2013).
} 
Table 2: Theil's U and DMW (CW) test, 1992Q4+h - 1998Q4+h

\begin{tabular}{|c|c|c|c|c|c|c|c|c|}
\hline \multirow[t]{2}{*}{ Country } & \multicolumn{4}{|c|}{ TVP Regression } & \multicolumn{4}{|c|}{ Fixed-Effect Panel Regression } \\
\hline & $\mathrm{U}(1)$ & $\mathrm{U}(4)$ & $\mathrm{U}(8)$ & $\mathrm{U}(12)$ & $\mathrm{U}(1)$ & $\mathrm{U}(4)$ & $\mathrm{U}(8)$ & $\mathrm{U}(12)$ \\
\hline \multicolumn{9}{|c|}{ TRon: Homogenous rule, without interest rate smoothing } \\
\hline Australia & 0.978 & 0.932 & 0.884 & $0.806^{+}$ & 0.990 & 1.016 & 0.971 & $0.875^{+}$ \\
\hline Canada & $0.963^{+}$ & $0.929^{+}$ & $0.791^{+}$ & $0.909^{+}$ & $0.981^{* *+}$ & $0.964^{+}$ & $0.928^{+}$ & $0.824^{+}$ \\
\hline Denmark & 0.996 & 1.019 & 0.974 & 1.061 & 1.005 & 1.025 & 0.984 & 1.025 \\
\hline UK & 0.986 & $0.900^{+}$ & $0.921^{+}$ & 2.234 & 1.048 & 1.289 & 1.489 & 1.420 \\
\hline Japan & 1.023 & 1.083 & 1.194 & 1.564 & 1.021 & 1.088 & 1.197 & 1.555 \\
\hline Korea & 0.998 & 0.984 & $0.951^{+}$ & $0.899^{+}$ & 0.998 & 0.982 & $0.946^{+}$ & $0.836^{+}$ \\
\hline Norway & 0.999 & 1.024 & $0.987^{+}$ & $0.926^{+}$ & 1.001 & 1.031 & 0.953 & $0.835^{+}$ \\
\hline Sweden & 1.018 & 1.058 & 0.969 & $0.799^{+}$ & 1.018 & 1.087 & 0.979 & $0.741^{+}$ \\
\hline Switzerland & 1.016 & 1.175 & 1.367 & 2.074 & 1.012 & 1.064 & 1.162 & 1.589 \\
\hline Austria & 1.032 & 1.068 & 1.085 & 1.340 & 1.015 & 1.037 & 1.037 & 1.172 \\
\hline Belgium & 1.013 & 1.036 & 0.965 & 0.964 & 1.003 & 1.019 & 0.981 & 0.990 \\
\hline France & 1.042 & 1.076 & 0.993 & $0.912^{* *+}$ & 1.003 & 1.026 & 0.962 & $0.866^{+}$ \\
\hline Germany & 1.021 & 1.080 & 1.197 & 1.453 & 1.019 & 1.038 & 1.043 & 1.230 \\
\hline Spain & 0.984 & 1.010 & $0.990^{+}$ & $0.636^{+}$ & 0.981 & 1.024 & $0.901^{+}$ & $0.659^{+}$ \\
\hline Italy & 1.015 & 1.032 & $1.011^{+}$ & $1.035^{+}$ & 1.009 & 0.994 & $0.771^{+}$ & $0.560^{+}$ \\
\hline Finland & 1.018 & 1.071 & 0.999 & $0.811^{+}$ & 1.015 & 1.038 & 0.949 & $0.827^{* *+}$ \\
\hline Netherlands & 1.026 & 1.072 & 1.096 & 1.414 & 1.011 & 1.034 & 1.043 & 1.189 \\
\hline No. U's $<1$ & 7 & 4 & 11 & 9 & 4 & 3 & 11 & 10 \\
\hline No. $D M W^{*}$ & 0 & 0 & 0 & 1 & 1 & 0 & 0 & 1 \\
\hline No. $C W^{*}$ & 1 & 2 & 6 & 9 & 1 & 1 & 4 & 9 \\
\hline \multicolumn{9}{|c|}{ TRos: Homogenous rule, with interest rate smoothing } \\
\hline Australia & 1.008 & 1.117 & 1.089 & $0.830^{+}$ & 0.996 & 1.071 & 1.048 & $0.881^{+}$ \\
\hline Canada & $0.964^{+}$ & $0.934^{+}$ & $0.943^{+}$ & $0.864^{+}$ & $0.967^{*+}$ & 0.922 & $0.867^{+}$ & $0.709^{+}$ \\
\hline Denmark & 1.003 & $0.953^{+}$ & $0.838^{+}$ & $0.966^{+}$ & 1.001 & $0.975^{+}$ & $0.781^{* *+}$ & $0.966^{+}$ \\
\hline UK & 1.074 & 1.443 & 1.958 & 1.821 & 1.055 & 1.350 & 1.610 & 1.487 \\
\hline Japan & 1.008 & 1.038 & 1.162 & 1.479 & 1.010 & 1.061 & 1.170 & 1.575 \\
\hline Korea & 0.999 & 0.987 & 0.959 & $0.904^{+}$ & 1.000 & 0.986 & 0.955 & $0.918^{+}$ \\
\hline Norway & 0.999 & $0.977^{+}$ & 0.958 & $0.948^{+}$ & 1.000 & 0.990 & $0.752^{* *+}$ & $0.697^{* *+}$ \\
\hline Sweden & 1.046 & 1.058 & 1.041 & $0.715^{+}$ & 1.009 & 1.059 & $0.832^{+}$ & $0.489 *+$ \\
\hline Switzerland & 1.013 & 1.032 & 1.146 & 2.093 & 0.997 & 0.986 & 0.984 & 1.511 \\
\hline Austria & 1.032 & 1.089 & 1.224 & 1.755 & 1.013 & 1.009 & 0.965 & 1.374 \\
\hline Belgium & 0.999 & $0.907^{*+}$ & $0.903^{+}$ & 1.647 & 0.991 & $0.941 *+$ & $0.775^{* *+}$ & $0.954^{+}$ \\
\hline France & 1.019 & 0.975 & $0.655^{*+}$ & $0.444^{*+}$ & 0.997 & 0.959 & $0.708^{* *+}$ & $0.613^{* *+}$ \\
\hline Germany & 1.036 & 1.110 & 1.143 & 1.605 & 1.012 & 1.015 & 0.986 & 1.429 \\
\hline Spain & 0.989 & 1.005 & $0.819^{+}$ & $0.381 *+$ & 0.994 & 1.021 & $0.752^{+}$ & $0.381 *+$ \\
\hline Italy & 1.018 & 1.035 & $1.039^{+}$ & 1.022 & 1.009 & 1.024 & $0.791^{+}$ & $0.426^{+}$ \\
\hline Finland & 1.029 & 1.017 & 0.991 & $0.689^{*+}$ & 1.000 & 0.983 & $0.787^{*+}$ & $0.704^{* *+}$ \\
\hline Netherlands & 1.028 & 1.048 & 1.075 & 1.408 & 1.004 & 0.988 & 0.926 & 1.297 \\
\hline No. U's $<1$ & 5 & 6 & 8 & 9 & 6 & 9 & 14 & 11 \\
\hline No. $D M W^{*}$ & 0 & 1 & 1 & 3 & 1 & 1 & 5 & 5 \\
\hline No. $C W^{*}$ & 1 & 4 & 6 & 9 & 1 & 2 & 9 & 11 \\
\hline
\end{tabular}


Table 2: (continued)

\begin{tabular}{|c|c|c|c|c|c|c|c|c|}
\hline \multirow{2}{*}{ Country } & \multicolumn{4}{|c|}{ TVP Regression } & \multicolumn{4}{|c|}{ Fixed-Effect Panel Regression } \\
\hline & $\mathrm{U}(1)$ & $\mathrm{U}(4)$ & $\mathrm{U}(8)$ & $\mathrm{U}(12)$ & $\mathrm{U}(1)$ & $\mathrm{U}(4)$ & $\mathrm{U}(8)$ & $\mathrm{U}(12)$ \\
\hline \multicolumn{9}{|c|}{ TRen: Heterogeneous rule, without interest rate smoothing } \\
\hline Australia & 0.984 & 0.955 & 0.889 & $0.818^{+}$ & 0.980 & 0.983 & 0.958 & $0.933^{+}$ \\
\hline Canada & $0.957^{+}$ & $0.929^{+}$ & $0.783^{+}$ & $0.879^{+}$ & $0.971^{* *+}$ & 0.962 & $0.950^{+}$ & $0.702^{+}$ \\
\hline Denmark & 1.006 & $0.961 * *+$ & $0.942 * *+$ & 1.074 & 1.009 & 1.002 & $0.924^{+}$ & 1.179 \\
\hline UK & 1.078 & 1.343 & 1.436 & 1.855 & 1.050 & 1.251 & 1.414 & 1.387 \\
\hline Japan & 1.032 & 1.118 & 1.219 & 1.629 & 1.024 & 1.085 & 1.190 & 1.596 \\
\hline Korea & 0.999 & 0.987 & $0.955^{+}$ & $0.889^{+}$ & 0.998 & 0.985 & $0.970^{+}$ & $0.912^{+}$ \\
\hline Norway & 1.017 & 1.094 & 1.192 & 1.371 & 0.991 & 0.994 & 1.020 & 1.319 \\
\hline Sweden & 1.010 & 0.972 & 0.984 & $0.829^{+}$ & 0.986 & 0.963 & $0.743^{* *+}$ & $0.686^{* *+}$ \\
\hline Switzerland & 1.019 & 1.130 & 1.350 & 2.273 & 1.018 & 1.070 & 1.191 & 1.802 \\
\hline Austria & 1.070 & 1.314 & 1.476 & 1.776 & 1.030 & 1.093 & 1.095 & 1.234 \\
\hline Belgium & 1.074 & 1.275 & 1.435 & 1.832 & 0.992 & $0.979^{+}$ & $0.950^{+}$ & 1.114 \\
\hline France & 1.017 & 1.189 & 1.287 & 1.079 & 0.991 & $0.906^{* *+}$ & $0.719^{* *+}$ & $0.874^{+}$ \\
\hline Germany & 1.040 & 1.134 & 1.184 & 1.456 & 1.044 & 1.099 & 1.102 & 1.453 \\
\hline Spain & 0.987 & 0.955 & $0.702^{*+}$ & $0.481^{*+}$ & 1.000 & 0.968 & $0.713^{*+}$ & $0.663^{*+}$ \\
\hline Italy & 1.008 & 1.016 & $1.013^{+}$ & $0.901^{+}$ & 1.004 & 0.959 & $0.680^{+}$ & $0.470^{*+}$ \\
\hline Finland & 1.021 & 1.018 & 0.974 & $0.661^{*+}$ & $0.986^{*}$ & $0.936^{*+}$ & $0.723^{*+}$ & $0.846^{+}$ \\
\hline Netherlands & 1.084 & 1.205 & 1.270 & 1.463 & 1.023 & 1.095 & 1.147 & 1.353 \\
\hline No. U's $<1$ & 4 & 6 & 7 & 7 & 8 & 10 & 10 & 8 \\
\hline No. $D M W^{*}$ & 0 & 1 & 2 & 2 & 2 & 2 & 4 & 3 \\
\hline No. $C W^{*}$ & 1 & 2 & 5 & 7 & 1 & 3 & 9 & 8 \\
\hline
\end{tabular}

Notes: Forecasting performance of the TVP forecasting regression and the Fixed-effect (FE) panel regression with Taylor rule fundamentals defined as TRon, TRos and TRen. The benchmark model for both forecasting regressions is the driftless Random Walk (RW). The $\mathrm{U}(\mathrm{h})$ is the U-statistic for quarterly forecast horizons, h. For example, U(1) is the U-statistic for one-quarter-ahead forecast. Values less than one (in bold) indicate that the fundamentals-based regression generates a lower RMSFE than the RW, hence it forecasts better than the RW. The Table also reports the DMW (CW) test-statistic with bootstrapped (standard normal) critical values. Asterisks $(* 10 \%, * * 5 \%, * * * 1 \%)$ denote the level of significance at which the null hypothesis of equal RMSFE is rejected under the DMW test, while the $(+)$ sign denotes rejection of the same null under the CW test at $10 \%$ significance level. This is equivalent to a better average accuracy of the forecasts of the fundamentals-based regression relative to the benchmark. The last two rows at the bottom of the Table summarise the results by counting the number of U's less than one (No. of U's $<1$ ) and the number of rejections of the null under the DMW (CW) test, i.e., No. of DMW* $\left(\mathrm{CW}^{*}\right)$. The forecast sample is 1992Q4+h - 1998Q4+h.

Looking at the statistical significance of the differences in forecasting performance, two aspects stand out. First, with bootstrapped critical values we rarely detect significant forecast accuracy improvements against the RW. In the last sample for example, while the TVP regressions yields U-statistics below one for at least half of the currencies and horizons greater than 1-quarter, we find at most three cases of significant differences in forecasting performance. Second, when instead we focus on the CW test, we are able to establish statistically significant improvements for most of the currencies for which the U-statistic is below one. And the number of significant cases increases with the forecast 
Table 3: Theil's U and DMW (CW) test, 1999Q1+h - 2013Q1

\begin{tabular}{|c|c|c|c|c|c|c|c|c|}
\hline \multirow[t]{2}{*}{ Country } & \multicolumn{4}{|c|}{ TVP Regression } & \multicolumn{4}{|c|}{ Fixed-Effect Panel Regression } \\
\hline & $\mathrm{U}(1)$ & $\mathrm{U}(4)$ & $\mathrm{U}(8)$ & $\mathrm{U}(12)$ & $\mathrm{U}(1)$ & $\mathrm{U}(4)$ & $\mathrm{U}(8)$ & $\mathrm{U}(12)$ \\
\hline \multicolumn{9}{|c|}{ TRon: Homogenous rule, without interest rate smoothing } \\
\hline Australia & 1.024 & 1.104 & 1.222 & 1.358 & 1.014 & 1.047 & 1.115 & 1.253 \\
\hline Canada & 1.014 & 1.052 & 1.116 & 1.457 & 1.006 & 1.023 & 1.064 & 1.110 \\
\hline Denmark & 1.002 & 1.011 & 1.047 & 1.033 & 1.006 & 1.023 & 1.054 & 1.058 \\
\hline UK & 1.026 & 1.068 & 1.049 & 1.278 & 1.003 & 1.025 & 1.075 & 1.156 \\
\hline Japan & 1.003 & $0.977^{+}$ & $0.929^{+}$ & $0.861^{+}$ & 1.002 & 0.993 & $0.950^{+}$ & $0.857^{+}$ \\
\hline Korea & 1.073 & 1.131 & 1.085 & 1.165 & 1.029 & 1.085 & 1.128 & 1.243 \\
\hline Norway & 1.014 & 1.044 & 1.030 & 1.130 & 1.010 & 1.045 & 1.131 & 1.238 \\
\hline Sweden & 1.012 & 1.044 & 1.093 & 1.250 & 1.015 & 1.064 & 1.160 & 1.416 \\
\hline Switzerland & 0.994 & $0.974^{+}$ & $0.891^{+}$ & $0.738^{+}$ & 0.997 & 0.989 & 0.966 & $0.928^{+}$ \\
\hline Euro & 1.009 & 1.101 & 1.177 & 1.431 & 1.012 & 1.063 & 1.144 & 1.243 \\
\hline No. $U^{\prime} s<1$ & 1 & 2 & 2 & 2 & 1 & 2 & 2 & 2 \\
\hline No. $D M W^{*}$ & 0 & 0 & 0 & 0 & 0 & 0 & 0 & 0 \\
\hline No. $C W^{*}$ & 0 & 2 & 2 & 2 & 0 & 0 & 1 & 2 \\
\hline \multicolumn{9}{|c|}{ TRos: Homogenous rule, with interest rate smoothing } \\
\hline Australia & 1.018 & 1.049 & 1.174 & 1.410 & 1.014 & 1.038 & 1.120 & 1.319 \\
\hline Canada & 1.017 & 1.051 & 1.163 & 1.495 & 1.011 & 1.030 & 1.082 & 1.160 \\
\hline Denmark & 0.999 & 1.018 & 1.044 & 1.056 & 1.004 & 1.026 & 1.071 & 1.112 \\
\hline UK & 1.009 & 1.032 & 1.098 & 1.227 & 1.008 & 1.029 & 1.064 & 1.145 \\
\hline Japan & 1.002 & 0.997 & $0.969^{+}$ & $0.936^{+}$ & 0.999 & 0.988 & $0.955^{+}$ & $0.900^{+}$ \\
\hline Korea & 1.034 & 1.091 & 1.105 & 1.205 & 1.018 & 1.043 & 1.052 & 1.161 \\
\hline Norway & 1.005 & 1.004 & $0.963^{+}$ & $0.961^{+}$ & 1.006 & 1.021 & 1.059 & 1.098 \\
\hline Sweden & 1.014 & 1.051 & 1.092 & 1.298 & 1.020 & 1.082 & 1.208 & 1.519 \\
\hline Switzerland & 0.994 & $0.937^{+}$ & $0.789^{+}$ & $0.598^{+}$ & $0.990^{*}$ & $0.938^{*+}$ & $0.826^{* *+}$ & $0.711^{* *+}$ \\
\hline Euro & 1.008 & 1.064 & 1.174 & 1.339 & 1.006 & 1.039 & 1.113 & 1.203 \\
\hline No. $U^{\prime} s<1$ & 2 & 2 & 3 & 3 & 2 & 2 & 2 & 2 \\
\hline No. $D M W^{*}$ & 0 & 0 & 0 & 0 & 1 & 1 & 1 & 1 \\
\hline No. $C W^{*}$ & 0 & 1 & 3 & 3 & 0 & 1 & 2 & 2 \\
\hline \multicolumn{9}{|c|}{ TRen: Heterogeneous rule, without interest rate smoothing } \\
\hline Australia & 1.027 & 1.106 & 1.231 & 1.346 & 1.018 & 1.058 & 1.144 & 1.306 \\
\hline Canada & 1.015 & 1.052 & 1.121 & 1.494 & 1.010 & 1.035 & 1.098 & 1.184 \\
\hline Denmark & 1.006 & 1.018 & 1.040 & 1.036 & 1.000 & 0.996 & 1.000 & 0.984 \\
\hline UK & 1.014 & 1.019 & 1.042 & 1.256 & 1.001 & 1.037 & 1.120 & 1.201 \\
\hline Japan & 1.008 & 0.999 & $0.950^{+}$ & $0.960^{+}$ & 0.998 & 0.973 & $0.938^{+}$ & $0.901^{+}$ \\
\hline Korea & 1.076 & 1.137 & 1.121 & 1.198 & 1.033 & 1.088 & 1.136 & 1.268 \\
\hline Norway & $0.975^{+}$ & $0.958^{+}$ & $0.949^{+}$ & $0.968^{+}$ & $0.981^{* * *+}$ & 0.985 & 1.037 & 1.093 \\
\hline Sweden & 1.004 & 1.005 & 1.099 & 1.123 & 1.005 & 1.040 & 1.126 & 1.314 \\
\hline Switzerland & 0.996 & $0.952^{+}$ & $0.879^{+}$ & $0.692^{+}$ & $0.989 *+$ & $0.950 *+$ & $0.910 *+$ & $0.870^{* *+}$ \\
\hline Euro & 1.009 & 1.065 & 1.190 & 1.341 & 1.002 & 1.017 & 1.065 & 1.091 \\
\hline No. $U^{\prime} s<1$ & 2 & 3 & 3 & 3 & 3 & 4 & 2 & 3 \\
\hline No. $D M W^{*}$ & 0 & 0 & 0 & 0 & 2 & 1 & 1 & 1 \\
\hline No. $C W^{*}$ & 1 & 2 & 3 & 3 & 2 & 1 & 2 & 2 \\
\hline
\end{tabular}

Notes: See notes to Table 2. The forecast sample is 1999Q1+h - 2013Q1. 
Table 4: Theil's U and DMW (CW) test, 2007Q1+h - 2013Q1

\begin{tabular}{|c|c|c|c|c|c|c|c|c|}
\hline \multirow[t]{2}{*}{ Country } & \multicolumn{4}{|c|}{ TVP Regression } & \multicolumn{4}{|c|}{ Fixed-Effect Panel Regression } \\
\hline & $\mathrm{U}(1)$ & $\mathrm{U}(4)$ & $\mathrm{U}(8)$ & $\mathrm{U}(12)$ & $\mathrm{U}(1)$ & $\mathrm{U}(4)$ & $\mathrm{U}(8)$ & $\mathrm{U}(12)$ \\
\hline \multicolumn{9}{|c|}{ TRon: Homogenous rule, without interest rate smoothing } \\
\hline Australia & 1.019 & 1.103 & 1.311 & 1.548 & 1.007 & 1.018 & 1.061 & 1.218 \\
\hline Canada & 1.007 & 1.019 & 1.050 & 1.678 & 1.002 & 1.001 & 0.971 & 0.952 \\
\hline Denmark & 1.003 & 0.992 & 0.988 & 1.218 & 1.005 & 0.993 & 0.997 & 1.060 \\
\hline UK & 1.010 & 1.005 & $0.941^{+}$ & $0.754^{+}$ & 1.000 & 0.993 & $0.978^{+}$ & 0.985 \\
\hline Japan & 0.999 & $0.918^{+}$ & $0.815^{+}$ & $0.736^{+}$ & 0.997 & $0.890^{*+}$ & $0.777^{*+}$ & $0.703^{*+}$ \\
\hline Korea & 0.995 & 0.958 & 0.933 & 0.985 & 0.995 & 0.974 & 0.952 & 0.936 \\
\hline Norway & 1.009 & 1.026 & 0.996 & 1.062 & 1.004 & 1.006 & 0.978 & 0.953 \\
\hline Sweden & 1.004 & 1.011 & 1.047 & 1.128 & 1.007 & 1.021 & 1.023 & 1.303 \\
\hline Switzerland & 0.991 & $0.940^{+}$ & $0.752^{*+}$ & $0.495 *+$ & 0.991 & $0.954^{+}$ & $0.796^{+}$ & $0.639 *+$ \\
\hline Euro & 1.008 & 0.999 & $0.894^{*+}$ & $0.613^{*+}$ & 1.004 & 1.001 & 0.996 & $0.759^{+}$ \\
\hline No. U's $<1$ & 3 & 5 & 7 & 5 & 3 & 5 & 8 & 7 \\
\hline No. $D M W^{*}$ & 0 & 0 & 2 & 2 & 0 & 1 & 1 & 2 \\
\hline No. $C W^{*}$ & 0 & 2 & 4 & 4 & 0 & 2 & 3 & 3 \\
\hline \multicolumn{9}{|c|}{ TRos: Homogenous rule, with interest rate smoothing } \\
\hline Australia & 1.015 & 1.007 & 1.098 & 1.325 & 1.012 & 1.003 & 1.018 & 1.142 \\
\hline Canada & 1.009 & 1.020 & 1.117 & 1.755 & 1.008 & 1.000 & $0.952^{+}$ & 1.010 \\
\hline Denmark & 1.014 & 1.055 & 1.097 & 1.321 & 1.011 & 1.034 & 1.094 & 1.279 \\
\hline $\mathrm{UK}$ & 0.999 & $0.979^{+}$ & $0.903^{+}$ & $0.840^{+}$ & 1.003 & $0.979^{+}$ & $0.916^{+}$ & $0.868^{+}$ \\
\hline Japan & 1.007 & $0.967^{+}$ & $0.828^{+}$ & $0.773^{+}$ & 1.000 & $0.911^{+}$ & $0.797^{+}$ & $0.739^{+}$ \\
\hline Korea & 0.992 & 0.968 & 0.949 & 1.016 & 0.995 & 0.949 & 0.892 & 0.844 \\
\hline Norway & 1.012 & 0.999 & 0.955 & $0.794^{*+}$ & 1.013 & 1.007 & $0.934^{+}$ & $0.860^{+}$ \\
\hline Sweden & 1.002 & 1.016 & 1.063 & 1.211 & 1.017 & 1.032 & 1.024 & 1.374 \\
\hline Switzerland & 0.997 & $0.954^{+}$ & $0.675^{*+}$ & $0.388^{*+}$ & 0.993 & $0.941^{+}$ & $0.703^{+}$ & $0.480 * *+$ \\
\hline Euro & 1.005 & 1.004 & $0.896^{*+}$ & $0.686^{*+}$ & 1.012 & 1.028 & 1.051 & 1.038 \\
\hline No. U's $<1$ & 3 & 5 & 6 & 5 & 2 & 4 & 6 & 5 \\
\hline No. $D M W^{*}$ & 0 & 0 & 2 & 3 & 0 & 0 & 0 & 1 \\
\hline No. $C W^{*}$ & 0 & 3 & 4 & 5 & 0 & 3 & 5 & 4 \\
\hline \multicolumn{9}{|c|}{ TRen: Heterogeneous rule, without interest rate smoothing } \\
\hline Australia & 1.026 & 1.116 & 1.357 & 1.571 & 1.009 & 1.022 & 1.086 & 1.274 \\
\hline Canada & 1.007 & 1.019 & 1.048 & 1.751 & 1.004 & 1.002 & $0.989^{+}$ & 1.021 \\
\hline Denmark & 1.006 & 1.018 & 1.062 & 1.508 & 1.011 & 1.002 & 1.112 & 1.633 \\
\hline UK & 1.003 & $0.973^{+}$ & $0.909^{+}$ & $0.757^{+}$ & 0.997 & 1.006 & 1.030 & 1.075 \\
\hline Japan & 0.994 & $0.853^{*+}$ & $0.795^{+}$ & $0.854^{+}$ & 0.995 & $0.869^{*+}$ & $0.769^{+}$ & $0.770^{+}$ \\
\hline Korea & 1.007 & 0.984 & 0.980 & 1.081 & 0.991 & 0.953 & 0.910 & 0.908 \\
\hline Norway & $0.968^{+}$ & $0.942^{+}$ & $0.896^{+}$ & $0.740^{+}$ & $0.974^{* *+}$ & $0.944^{+}$ & $0.742^{+}$ & $0.643^{+}$ \\
\hline Sweden & 0.996 & 0.969 & 1.050 & $0.886^{*+}$ & 1.001 & 0.995 & 0.966 & 1.188 \\
\hline Switzerland & 0.993 & $0.923^{+}$ & $0.690^{+}$ & $0.449 *+$ & 0.983 & $0.903^{+}$ & $0.648^{+}$ & $0.680^{*+}$ \\
\hline Euro & 1.005 & 0.985 & $0.897^{*+}$ & $0.794^{*+}$ & 1.015 & 1.009 & 1.161 & 1.248 \\
\hline No. U's $<1$ & 4 & 7 & 6 & 6 & 5 & 5 & 6 & 4 \\
\hline No. $D M W^{*}$ & 0 & 1 & 1 & 3 & 1 & 1 & 0 & 1 \\
\hline No. $C W^{*}$ & 1 & 4 & 5 & 6 & 1 & 3 & 4 & 3 \\
\hline
\end{tabular}

Notes: See notes to Table 2. The forecast sample is 2007Q1+h - 2013Q1. 
horizon. Again, results from the TVP regression in the last forecast sample illustrate this assertion. At $h=4$, when the regression is conditioned on TRen fundamentals it significantly improves upon the RW for four out of the seven for which the U-statistic is less than one. As the forecast horizon increases, cases of significance raise to five out of six at $h=8$, and to all the six currencies for which it generates a lower RMSFE than the RW at $h=12$ quarters.

Shifting the focus to the FE panel regression, results show that it produces a smaller forecast error than the RW in the first and last forecast samples, and also for horizons beyond 1-quarter. In the first forecast sample, it outperforms the RW for at least half of the currencies at $h=8$ and 12 quarters, when conditioned on TRon and TRos information sets. The strongest performance occurs at $h=8$ and with TRos fundamentals, where it yields a lower RMSFE for as many as 14 out of the 17 currencies. Like in the TVP regression, the differences in forecast errors are mostly statistically insignificant on the basis of the bootstrapped $p$-values. But based on the asymptotic CW test, the null of equal RMSFE is often rejected. In fact, in this forecast sample the rejections are on average higher when the forecasts are from the FE panel regression rather than from the TVP regression.

In the last forecast sample (2007Q1+h - 2013Q1) the FE panel regression produces a lower RMSFE than the RW for a minimum of five out of 10 currencies mainly at $h=$ 4, 8, 12 quarters. The best performance is achieved when the regression is conditioned on TRon fundamentals, where it outforecasts the RW for eight and seven currencies at $h=8$ and $h=12$, respectively. And once more, the differences in forecast accuracy are mostly statistically significant under the CW test with standard critical values. These significant cases, however, are on average fewer than those from the TVP regression in this sample. We also note that both, the FE panel regression and the TVP regression performed unsatisfactorily in the forecast sample spanning 1999Q1+h - 20013Q1 in Table 3. In this sample, forecasts based on the naive RW are more accurate for most currencies/horizons.

On balance, and based on the U-statistic, the FE panel regression had a better average performance in the first or early sample, while the TVP regression outperformed the 
RW for a large number of currencies in the last sample. Using the usual CW test, we also detected more cases of statistically significant differences in performance in the first sample (last sample) when forecasting with the FE panel regression (TVP regression). On the contrary, when we apply bootstrapped $p$-values we hardly detect significant forecast accuracy improvements, irrespective of the forecasting regression. Rogoff and Stavrakeva (2008) discuss at length these typical findings, attributing them to the incorrect size of the CW test. For our purpose, we note the importance of the CW test in placing our results in the context of the existing studies.

Focusing on the RMSFE metric, Figure 1 illustrates what determines a U-statistic of certain magnitude for each regression. It depicts the predicted path of the change in exchange rate based on fundamentals from a TVP Taylor rule versus from a constant parameter (CP) Taylor rule, juxtaposed with the observed $h$-quarter change in the exchange rate. Recall that the former fundamentals are employed in the TVP forecasting regression, while the latter in the FE panel forecasting regression. The example is based on the UK, for the last forecast sample, at $h=1$ and $h=12$, and the Taylor rule specification with heterogeneous coefficients and no smoothing (TRen). The U-statistics are $1.003(h=1)$ and $0.757(h=12)$ for the TVP regression, and $0.997(h=1)$ and 1.075 $(h=12)$ for the FE panel regression.

Panel A shows the case of the forecasting regression with TVP Taylor rule fundamentals. At 1-quarter horizon the regression fails to improve upon the RW; and as depicted, this might be due to its failure to predict the path of the subsequent change in the Pound sterling/USD exchange rate in several periods of the forecast sample, resulting in a U-statistic above one. For instance, while it predicts a fall in the Pound sterling from 2007Q2 up to 2008Q4, the data shows an opposite path. In the following periods the regression predicts the correct movements until 2009Q4, failing subsequently until 2010Q3. In the remaining periods it does reasonably well, except between 2011Q1 and 2011Q3. By contrast, at the 12-quarters forecast horizon it predicts almost all the subsequent movements in the exchange rate, yielding a U-statistic significantly less than one $(\mathrm{U}=0.757)$. 
Figure 1: Predicted Change in Exchange Rate, TVP Taylor Rules versus CP Taylor Rules

Panel A: Predictions based on a TVP Taylor rule

$\mathrm{UK} ; \mathrm{h}=1 ; \mathrm{U}-\mathrm{stat}=1.003$

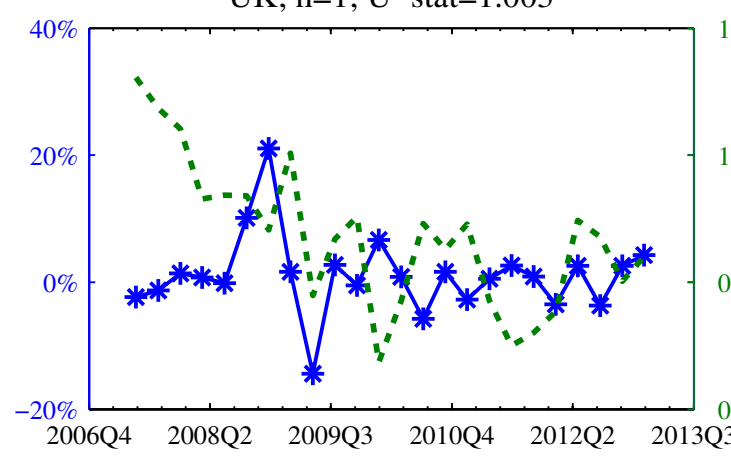

$\mathrm{UK} ; \mathrm{h}=12 ; \mathrm{U}-\mathrm{stat}=0.757$

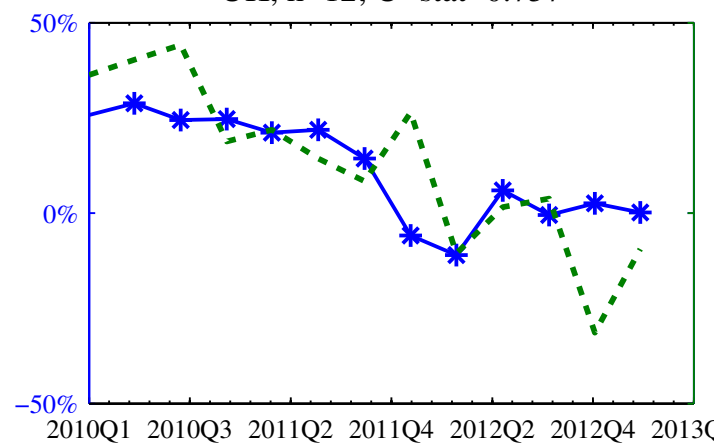

Panel B: Predictions based on a CP Taylor rule

$\mathrm{UK} ; \mathrm{h}=1 ; \mathrm{U}-\mathrm{stat}=0.997$

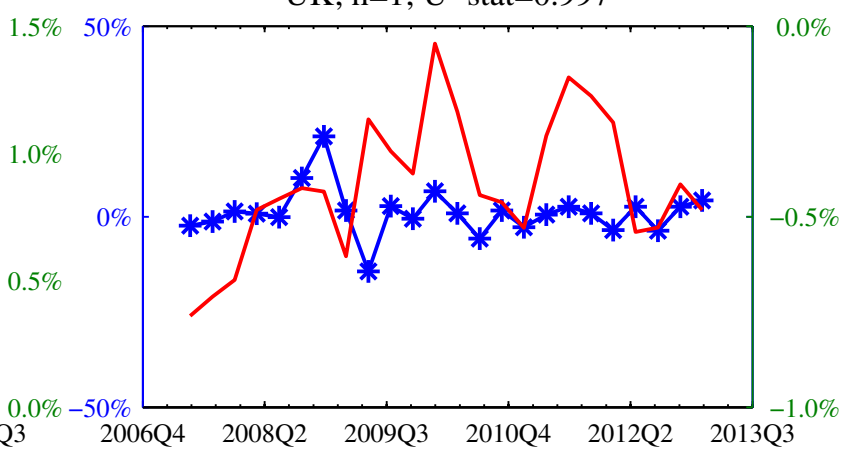

UK; h=12; U-stat=1.075

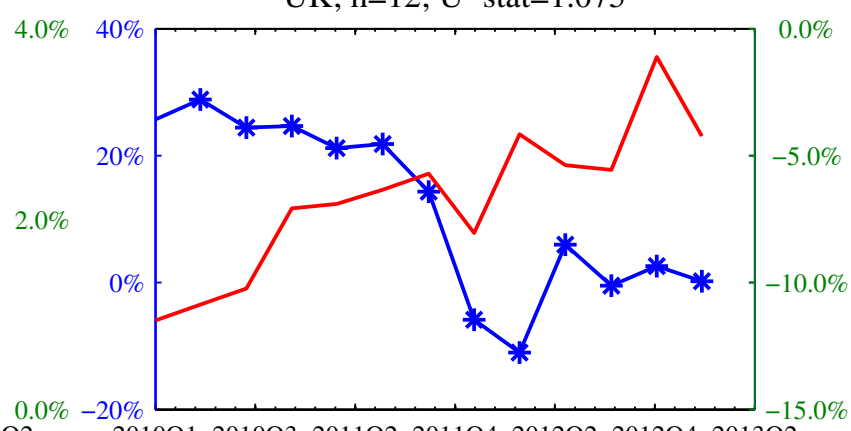

2010Q1 2010Q3 2011Q2 2011Q4 2012Q2 2012Q4 2013Q2

* Observed h-quarter change in the exchange rate (left scale)

- - - - - - Prediction based on fundamentals from a TVP Taylor rule (doted line, right scale)

Prediction based on fundamentals from a CP Taylor rule (line, right scale)

Notes: Predicted change in exchange rate based on fundamentals from a TVP Taylor rule versus a Constant Paramater (CP) Taylor rule, juxtaposed with the observed $h$-quarter change in the exchange rate. The Taylor rule specification assumes heterogeneous coefficients and no smoothing (TRen). The fundamentals, or more precisely the interest rate differentials, are estimated recursively to nest the forecasting method. The out-of-sample period is 2007Q1+h-2013Q1.

Panel B shows predictions based on the FE panel regression with fundamentals from the constant parameter Taylor rule. At 1-quarter forecast horizon, the regression is able to accurately signal the subsequent change in the Pound sterling exchange rate for the most part of the forecast sample. But since there are also some periods were it fails, for example between 2009Q1- 2009Q3 and 2011Q3-2012Q2, the gains in terms of reduction in the RMSFE are small (0.3\%). In contrast, at 12-quarters horizon, it correctly signals the changes in the Pound sterling exchange rate only in a few cases, resulting in a U-statistic above one (1.075).

To shed more light on the sources of differences in forecasting performance, Figure 2 shows the slope coefficients we use to forecast, together with the time $t$ conditioning 
Figure 2: Slope Coefficients and Taylor Rule Fundamentals

Panel A: Slope and TR Fundamentals, TVP Regression
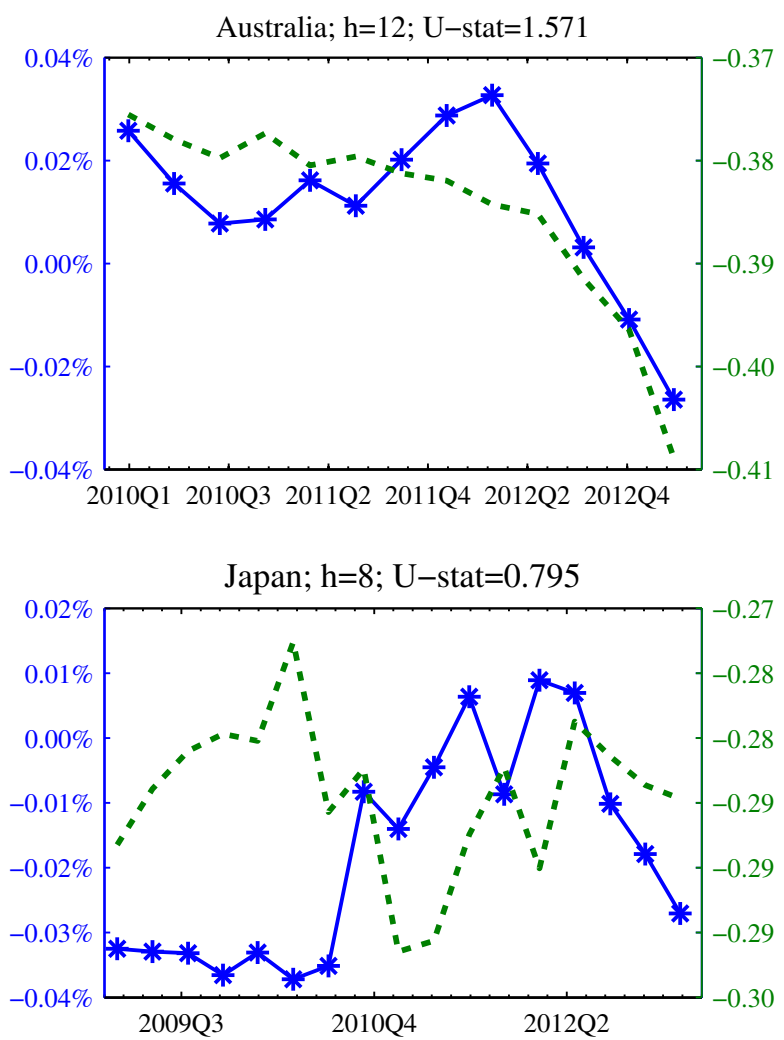

* Taylor rule fundamentals (left scale)

- - - - - - Slope Coefficient - TVP Regression (doted line, right scale)

Slope Coefficient - FE Regression (line, right scale)
Panel B: Slope and TR Fundamentals, FE Regression
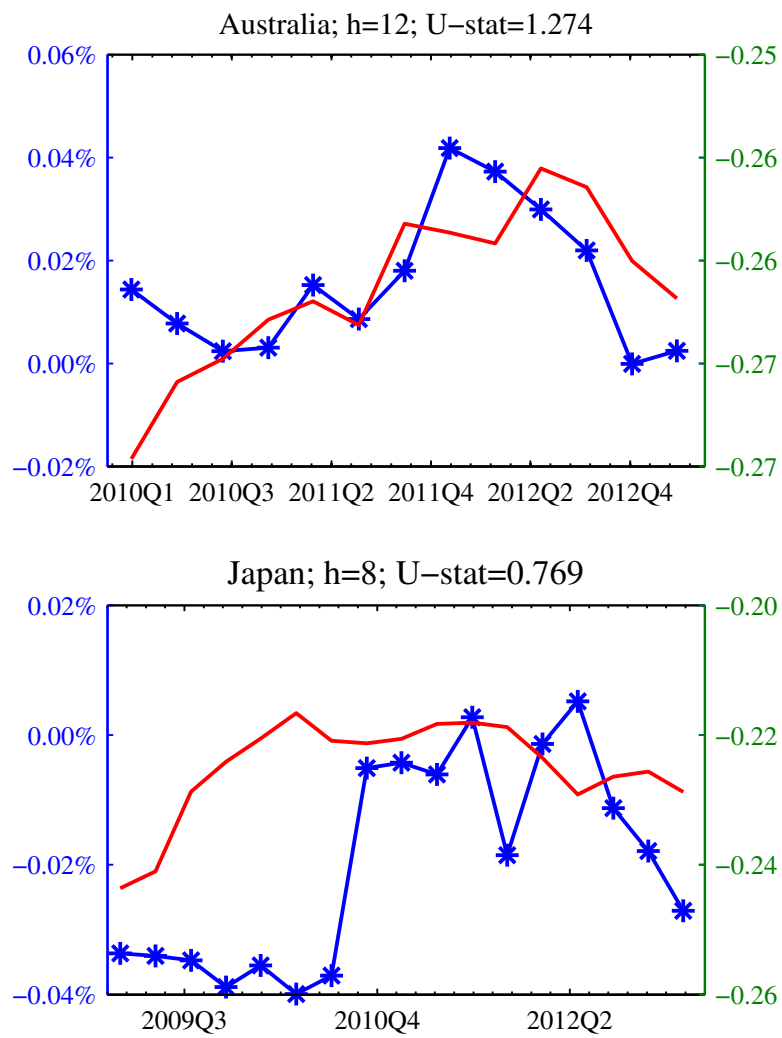

Notes: Panel A - Slope coefficients from the TVP forecasting regression, juxtaposed with Taylor rule fundamentals estimated via a TVP regression. Panel B - Slope coefficients from the FE panel regression, juxtaposed with Taylor rule fundamentals estimated from a constant-paramater linear regression. The Taylor rule specification assumes heterogeneous coefficients and no smoothing (TRen). The coefficients and the fundamentals are estimated recursively in an expanding window of data to nest the forecasting approach. The out-of-sample period is 2007Q1+h - 2013Q1.

information. Panel A shows the coefficients from the TVP forecasting approach and Panel B from the FE panel regression. We again consider the Taylor specification with heterogeneous coefficients, the last forecast sample, and cases of Australia $(h=12)$ and Japan $(h=8)$. The countries and forecast horizons were chosen to illustrate cases where both regressions failed to improve upon the RW and situations where they succeeded.

Clearly, the slope coefficients are higher in absolute value in the TVP regression than in the FE panel regardless of the forecasting performance. This implies that in the TVP approach, the larger is the magnitude of deviation of the exchange rate from the fundamental, the higher is the speed of correction towards its fundamental implied 
level. Whether this leads to a better forecasting performance depends on how well this speed of adjustment accounts for the path of the exchange rate $h$-periods in the future. Since exchange rates deviations from the level implied by fundamentals are frequent, the speed of adjustment (which is estimated in-sample) may fail to account for the path of the exchange rate out-of-sample. It may not be high enough to correct large short-term deviations. Similarly, the relatively small (absolute) values of the slope coefficients from the FE panel regression do not necessarily imply poor forecasting performance. As the graphs illustrate, either a small or a high degree of adjustment may be consistent with satisfactory or unsatisfactory forecasting performance.

The performance of the FE panel regression in our sample is partially similar to the results in Engel et al. (2008). Using a FE panel regression that includes time effects and fixed effects they find that the driftless RW outperforms Taylor-rule based regressions at their short ( $h=1$ quarter) and long ( $h=16$ quarters) forecast horizons. Here, while the findings for the short-horizons forecasts are similar, for long-horizons ( $h=8$ and $h=12$ ) we find improvement upon the RW. There are, nonetheless, a number of differences between their analysis and ours. Probably the most significant are: (i) the differences in the forecast samples considered and the sample span, ${ }^{14}$ and (ii) their use of a Taylor rule specification with posited coefficients, whereas here we estimate the coefficients.

\section{Summary results and robustness checks}

Table 5 sums up our empirical results. It provides the answer to the following question: "Based on RMSFE, does the regression conditioned on each of the Taylor rule fundamentals we consider outperform the RW for at least half of the currencies in the sample? If Yes, for how many currencies it does so?" It turns out that the FE panel regression accumulates relatively many "Yes" answers in the first forecast sample; and mostly for $h=4,8,12$ quarters. The TVP regression aggregates positive answers for a relatively large number of currencies in the last forecast sample and similar forecasting

\footnotetext{
${ }^{14}$ Engel's et al. (2008) sample covers the period 1973Q1-2005Q4, whilst our sample extends for an extra eight years from 2005Q4.
} 
Table 5: Based on RMSFE, Does the Regression Outperform the RW for at Least Half of the Currencies in the Sample?

\begin{tabular}{|c|c|c|c|c|c|c|c|c|}
\hline \multirow{2}{*}{$\begin{array}{l}\text { Fundamen- } \\
\text { tals } \\
\text { from: }\end{array}$} & \multicolumn{4}{|c|}{ TVP Regression } & \multicolumn{4}{|c|}{ FE Panel Regression } \\
\hline & $\mathrm{h}=1$ & $\mathrm{~h}=4$ & $\mathrm{~h}=8$ & $\mathrm{~h}=12$ & $\mathrm{~h}=1$ & $\mathrm{~h}=4$ & $\mathrm{~h}=8$ & $\mathrm{~h}=12$ \\
\hline \multicolumn{9}{|c|}{ Forecast Sample: 1992Q4+h - 1998Q4+h; N=17 } \\
\hline TRon & No & No & Yes (11) & Yes $(9)$ & No & No & Yes $(11)$ & Yes $(10)$ \\
\hline TRos & No & No & No & Yes (9) & No & Yes $(9)$ & Yes $(14)$ & Yes (11) \\
\hline TRen & No & No & No & No & No & Yes $(10)$ & Yes $(10)$ & No \\
\hline \multicolumn{9}{|c|}{ Forecast Sample: 1999Q1+h - 2013Q1; N=10 } \\
\hline TRon & No & No & No & No & No & No & No & No \\
\hline TRos & No & No & No & No & No & No & No & No \\
\hline TRen & No & No & No & No & No & No & No & No \\
\hline \multicolumn{9}{|c|}{ Forecast Sample: $2007 \mathrm{Q} 1+\mathrm{h}-2013 \mathrm{Q} 1 ; \mathrm{N}=10$} \\
\hline TRon & No & Yes $(5)$ & Yes $(7)$ & Yes $(5)$ & No & Yes $(5)$ & Yes $(8)$ & Yes $(7)$ \\
\hline TRos & No & Yes $(5)$ & Yes $(6)$ & Yes $(5)$ & No & No & Yes $(6)$ & Yes $(5)$ \\
\hline TRen & No & Yes $(7)$ & Yes (6) & Yes (6) & Yes (5) & Yes (5) & Yes (6) & No \\
\hline
\end{tabular}

Notes: Summary of the overall forecasting performance of the TVP regression and the FE panel regression, conditioned on alternative Taylor rule fundamentals - see Table 1. The Table provides the answer to the question: "Based on RMSFE, does the regression outperform the driftless RW for at least half of the currencies in the sample?" When the answer is "Yes", we indicate the corresponding number of currencies in brackets. For each forecast sample, $\mathrm{N}$ is the total number of currencies in that sample.

horizons. The highest improvement occurs when we allow for Taylor rules with heterogeneous coefficients across countries. Hence, our forecasting approach appears to be useful in recent periods, where significant shifts in fundamentals occurred and exchange rate volatility has been markedly high (see, e.g., Mumtaz and Sunder-Plassmann, 2013). ${ }^{15}$

To verify how robust our results are, we examined different scenarios. These included: (i) forecasting using a linear regression in rolling windows; (ii) changing the base currency from the U.S. dollar to the Pound sterling; (iii) using unemployment gap rather than output gap in Taylor rule specifications; (iv) using monthly data instead of quarterly data, and (v) employing an alternative metric for forecast evaluation - the direction of change statistic. In Table 6 we summarize the results for the first four checks, which are based on the RMSFE metric. In essence, as we elaborate next, the results from the TVP

\footnotetext{
${ }^{15}$ In unreported results, we further experimented comparing directly the forecasts from the TVP regression with those from the FE panel regression, instead of normalizing forecasts from both approached to the RW. Essentially, we found similar results regarding the better performance of the FE panel relative to the TVP regression in the early forecasting sample and the opposite in the last forecast sample.
} 
Table 6: In Robustness Checks and Based on RMSFE, Does the Regression Outperform the RW for at Least Half of the Currencies in the Sample?

Panel A: TVP Regressions in Recursive Approach versus Linear Regression in Rolling Windows

\begin{tabular}{|c|c|c|c|c|c|c|c|c|}
\hline \multirow{2}{*}{$\begin{array}{l}\text { Fundamen- } \\
\text { tals } \\
\text { from: }\end{array}$} & \multicolumn{4}{|c|}{ TVP Regression } & \multicolumn{4}{|c|}{ Linear Regression in Rolling Windows } \\
\hline & $\mathrm{h}=1$ & $\mathrm{~h}=4$ & $\mathrm{~h}=8$ & $\mathrm{~h}=12$ & $\mathrm{~h}=1$ & $\mathrm{~h}=4$ & $\mathrm{~h}=8$ & $\mathrm{~h}=12$ \\
\hline \multicolumn{9}{|c|}{ Forecast Sample: 1992Q4+h - 1998Q4+h; N=17 } \\
\hline TRon & No & No & Yes(11) & $\operatorname{Yes}(9)$ & No & No & No & No \\
\hline TRos & No & No & No & $\operatorname{Yes}(9)$ & No & No & No & No \\
\hline TRen & No & No & No & No & No & No & No & No \\
\hline \multicolumn{9}{|c|}{ Forecast Sample: 1999Q1+h - 2013Q1; N=10 } \\
\hline TRon & No & No & No & No & No & No & No & No \\
\hline TRos & No & No & No & No & No & No & No & No \\
\hline TRen & No & No & No & No & No & No & No & No \\
\hline \multicolumn{9}{|c|}{ Forecast Sample: 2007Q1+h - 2013Q1; N=10 } \\
\hline TRon & No & $\operatorname{Yes}(5)$ & $\operatorname{Yes}(7)$ & $\operatorname{Yes}(5)$ & No & No & $\operatorname{Yes}(6)$ & No \\
\hline TRos & No & $\operatorname{Yes}(5)$ & $\operatorname{Yes}(6)$ & $\operatorname{Yes}(5)$ & No & $\operatorname{Yes}(5)$ & $\operatorname{Yes}(5)$ & $\operatorname{Yes}(5)$ \\
\hline TRen & No & $\operatorname{Yes}(7)$ & Yes $(6)$ & $\operatorname{Yes}(6)$ & No & $\operatorname{Yes}(6)$ & $\operatorname{Yes}(6)$ & $\operatorname{Yes}(5)$ \\
\hline
\end{tabular}

Panel B: Change in Base Currency, Forecast Sample: 2007Q1+h - 2013Q1; N=10

\begin{tabular}{|c|c|c|c|c|c|c|c|c|}
\hline & \multicolumn{4}{|c|}{ TVP Regression } & \multicolumn{4}{|c|}{ FE Panel Regression } \\
\hline & $\mathrm{h}=1$ & $\mathrm{~h}=4$ & $\mathrm{~h}=8$ & $\mathrm{~h}=12$ & $\mathrm{~h}=1$ & $\mathrm{~h}=4$ & $\mathrm{~h}=8$ & $\mathrm{~h}=12$ \\
\hline TRon & Yes $(5)$ & Yes $(6)$ & Yes (6) & Yes $(7)$ & No & No & Yes $(5)$ & Yes (5) \\
\hline TRos & No & Yes (6) & Yes (5) & Yes (8) & No & Yes (5) & Yes $(5)$ & Yes (6) \\
\hline TRen & Yes $(6)$ & Yes $(6)$ & Yes $(5)$ & Yes (5) & No & No & Yes $(5)$ & No \\
\hline
\end{tabular}

Panel C: Taylor Rules with Unemployment Gap, Forecast Sample: 2007Q1+h - 2013Q1; N=9

\begin{tabular}{|c|c|c|c|c|c|c|c|c|}
\hline & \multicolumn{4}{|c|}{ TVP Regression } & \multicolumn{4}{|c|}{ FE Panel Regression } \\
\hline & $\mathrm{h}=1$ & $\mathrm{~h}=4$ & $\mathrm{~h}=8$ & $\mathrm{~h}=12$ & $\mathrm{~h}=1$ & $\mathrm{~h}=4$ & $\mathrm{~h}=8$ & $\mathrm{~h}=12$ \\
\hline TRon & No & No & No & Yes (5) & No & No & Yes $(5)$ & No \\
\hline TRos & No & No & No & Yes (5) & No & Yes (5) & Yes $(6)$ & No \\
\hline TRen & No & Yes (5) & Yes (5) & Yes (6) & No & No & No & No \\
\hline
\end{tabular}

Panel D: Forecasting with Monthly Data, Forecast Sample: 2007Q1+h - 2013Q1; N=10

\begin{tabular}{|c|c|c|c|c|c|c|c|c|}
\hline & \multicolumn{4}{|c|}{ TVP Regression } & \multicolumn{4}{|c|}{ FE Panel Regression } \\
\hline & $\mathrm{h}=3 \mathrm{M}$ & $\mathrm{h}=12 \mathrm{M}$ & $\mathrm{h}=24 \mathrm{M}$ & $\mathrm{h}=36 \mathrm{M}$ & $\mathrm{h}=3 \mathrm{M}$ & $\mathrm{h}=12 \mathrm{M}$ & $\mathrm{h}=24 \mathrm{M}$ & $\mathrm{h}=36 \mathrm{M}$ \\
\hline TRon & No & No & Yes (6) & Yes (5) & No & Yes (5) & Yes (7) & Yes (7) \\
\hline TRos & No & Yes (5) & Yes (6) & Yes (6) & No & No & Yes (7) & Yes (5) \\
\hline TRen & Yes (6) & Yes (5) & Yes (7) & Yes (5) & Yes (6) & No & Yes (5) & No \\
\hline
\end{tabular}

Notes: Summary of the overall forecasting performance of the regressions under different robustness checks scenarios - see Section 6. The Table provides the answer to the question: "Based on RMSFE, does the regression outperform the driftless RW for at least half of the currencies in the sample?" When the answer is "Yes", we indicate the corresponding number of currencies in brackets. For each forecast sample, $\mathrm{N}$ is the total number of currencies in that sample. 
forecasting approach remain coherent. Repeatedly, the TVP regression conditioned on Taylor rules with heterogeneous coefficients delivers the highest performance. That is, for horizons greater than 1-quarter and regardless of the scenario under consideration, it outperformed the driftless RW for at least half of the currencies in the late sample. Regarding the FE panel, its ability to yield a smaller RMSFE than the RW for over half of the currencies in this sample is relatively less robust. When we check the ability of these regressions to predict the direction of exchange rate change, both, the TVP regression and the FE panel outperform the RW for at least half of the currencies mostly at horizons beyond 1-quarter. There are, however, small distinctions in the statistical significance of the magnitudes we found, with the FE panel regression exhibiting somewhat less significant cases (Table 7$).{ }^{16}$

\subsection{Forecasting with a linear regression in rolling windows}

Our main forecasting approach allows for time-varying coefficients in the regression used to estimate Taylor rule fundamentals and in the forecasting model. In addition, all the parameters are estimated recursively. Molodtsova and Papell (2009, 2013) and Rossi (2013) estimate Taylor rule fundamentals via OLS in a single-equation constantparameter (SECP) model. These fundamentals are then employed as conditioning information in subsequent SECP forecasting regression, in a rolling window forecasting approach. Accordingly, we explored their methodology. In particular, we defined the rolling windows such that the number of forecasts generated using this method matches with the forecasts in the recursive forecasting method. We focused in the first and last forecast samples and two Taylor rule specifications, TRon and TRen. Using this forecasting approach improved upon the RW for at least half of the currencies in the last forecast sample when conditioned on TRen fundamentals. In this case, it yielded better forecasts for six (at $h=4,8)$ and five $(h=12)$ out of the 10 currencies considered. We note though that in this sample and for the same Taylor specification, the TVP regression outperformed the RW for slightly more currencies: seven (at $h=4)$ and six (at $h=8,12$ ),

\footnotetext{
${ }^{16}$ To save space we omit detailed results for the first four robustness checks. These results are available in Section 4 of the Online Appendix.
} 
see Table 4 in Section 5. Hence, our TVP regression in a recursive forecasting approach performed marginally better than this approach. ${ }^{17}$

\subsection{Change in base currency}

Chen et al. (2010) and Engel et al. (2015) note the importance of verifying the sensitiveness of the exchange rate models forecasting performance to a different base numeraire. Following this idea, we replaced the U.S. dollar base currency by the Pound sterling (GBP), defined all the home country variables relative to the UK, and repeated the forecasting exercise for the last forecast sample. In this setting, the TVP regression generated the strongest performance: it significantly outperformed the RW for over half of the currencies in nearly all forecast horizons, and regardless of the Taylor rule specification. The largest number of exchange rates for which it outforecasted the RW occurred at the longest horizon, with eight out of 10 currencies. The FE panel regression generated more accurate forecasts mostly at longer horizons and for no more than six currencies.

\subsection{Taylor rules with unemployment gap}

Monetary policy rules can focus on the unemployment gap rather than the output gap. Molodtsova and Papell (2013) find that Taylor rules with the unemployment gap outperform specifications with the output gap. We therefore replaced the output gap by the unemployment gap and proceeded with the forecasting exercise, focusing on the last forecast sample (2007Q1+h - 2013Q1). Due to unavailability of data on unemployment gap for all the countries in the sample, here we forecasted nine exchange rates. In our results, the TVP regression conditioned on the Taylor rule with heterogeneous coefficients (TRen) delivered the most prominent results. At horizons beyond 1-quarter, it generated more precise forecasts than the RW for five to six currencies out of the nine considered. The FE panel model with TRen improved upon the RW for no more than four currencies

\footnotetext{
${ }^{17}$ In comparison with other studies that employ a SECP forecasting regression conditioned on Taylor rule fundamentals estimated with a SECP, our results differ from theirs. For example, focusing on monthly data up to June 2006, Molodtsova and Papell (2009) find improvement upon the RW benchmark for as many as 10 out of 12 OECD currencies at one-month-ahead forecast horizon. Rossi (2013) uses monthly data up to 2011 and finds improvement over the RW for seven out of 17 currencies at one-month forecast horizon, but for none of the currencies at long horizons.
} 
across all forecast horizons. But it somewhat performed better than the benchmark for at least half of the currencies, when conditioned on TRon at $h=8$ and TRos at $h=4,8$. $^{18}$

\subsection{Forecasting with monthly data}

To verify how results would vary to the frequency of data used we experimented with monthly data. We concentrated on the last forecast sample and four monthly forecast horizons, comprising $h=3 M, h=12 M, h=24 M$, and $h=36 M$, which are comparable to our quarterly horizons. Here our results confirmed the strong performance of the TVP forecasting approach conditioned on Taylor rules with heterogeneous coefficients (TRen). This approach outperformed the RW for at least half of the currencies at all forecasting horizons, reaching as many as seven of the nine currencies examined. The FE panel regression forecasted better than the benchmark for over four currencies mainly at horizons beyond 12-months. ${ }^{19}$

\subsection{Forecast evaluation based on the direction of change statistic}

Finally, we followed Cheung et al. (2005) and evaluated our models forecasting performance based on the direction of change statistic. The metric is computed as the proportion of times that the fundamentals-based regression predicts the correct sign of the exchange rate change. Values above (below) 0.5 indicate that the regression is able (unable) to predict the direction of exchange rate change. Cheung et al. (2005) also provide details for computing the Diebold and Mariano (1995) test of equal forecasting performance of the fundamentals-based regression relative to a naive benchmark that predicts that the exchange rate might go down or up with the same probability. Results for the last forecast sample are shown in Table 7 . Both, the TVP regression and the FE panel exhibit values greater than 0.5 for at least half of the currencies mainly for horizons beyond 1-quarter. But for the majority of these currencies for which both regressions do well, there are more significant differences in performance when using the TVP regression

\footnotetext{
${ }^{18}$ In comparison with Molodtsova and Papell (2013), the performance of our TVP regression, as well as of the FE panel regression with either Taylor rule specification, was generally inferior to regressions based on the output gap.

${ }^{19}$ We excluded Australia due to unavailability of CPI data at monthly frequency for this country.
} 
Table 7: Direction of Change Statistics and DMW test, 2007Q1+h - 2013Q1

\begin{tabular}{|c|c|c|c|c|c|c|c|c|}
\hline \multirow[t]{2}{*}{ Country } & \multicolumn{4}{|c|}{ TVP Regression } & \multicolumn{4}{|c|}{ Fixed-Effect Panel Regression } \\
\hline & $\mathrm{h}=1$ & $\mathrm{~h}=4$ & $\mathrm{~h}=8$ & $\mathrm{~h}=12$ & $\mathrm{~h}=1$ & $\mathrm{~h}=4$ & $\mathrm{~h}=8$ & $\mathrm{~h}=12$ \\
\hline \multicolumn{9}{|c|}{ TRon: Homogenous rule without interest rate smoothing } \\
\hline Australia & 0.333 & 0.286 & 0.294 & 0.077 & 0.333 & 0.286 & 0.294 & 0.154 \\
\hline Canada & 0.375 & 0.381 & 0.471 & 0.231 & 0.500 & 0.333 & 0.471 & 0.615 \\
\hline Denmark & 0.417 & $0.667^{*}$ & 0.647 & 0.154 & 0.417 & 0.524 & 0.588 & 0.462 \\
\hline UK & 0.542 & $0.667^{*}$ & $0.706 * *$ & $0.769 * *$ & $0.667^{*}$ & 0.571 & 0.647 & 0.538 \\
\hline Japan & 0.583 & $0.810 * * *$ & $0.824^{* * *}$ & $0.923^{* * *}$ & 0.542 & $0.810 * * *$ & $0.882^{* * *}$ & $0.923 * * *$ \\
\hline Korea & 0.417 & 0.476 & 0.471 & 0.462 & 0.375 & 0.476 & 0.471 & 0.462 \\
\hline Norway & 0.375 & 0.476 & 0.647 & 0.385 & 0.417 & 0.524 & 0.588 & 0.462 \\
\hline Sweden & 0.583 & 0.476 & 0.412 & 0.538 & 0.542 & 0.476 & 0.412 & 0.538 \\
\hline Switzerland & 0.542 & $0.667^{*}$ & $0.824^{* * *}$ & $1.000^{* * *}$ & 0.583 & $0.667^{*}$ & $0.824^{* * *}$ & $0.923^{* * *}$ \\
\hline Euro & 0.500 & 0.571 & $0.706^{* *}$ & $0.846 * * *$ & 0.375 & 0.429 & 0.294 & 0.154 \\
\hline Direction $>0.5$ & 4 & 5 & 6 & 5 & 4 & 5 & 5 & 5 \\
\hline No. $D M W^{*}$ & 0 & 4 & 4 & 4 & 1 & 2 & 2 & 2 \\
\hline \multicolumn{9}{|c|}{ TRos: Homogenous rule with interest rate smoothing } \\
\hline Australia & 0.333 & 0.333 & 0.294 & 0.077 & 0.500 & 0.524 & 0.471 & 0.077 \\
\hline Canada & 0.375 & 0.381 & 0.176 & 0.231 & 0.375 & 0.333 & 0.588 & 0.462 \\
\hline Denmark & 0.333 & 0.381 & 0.353 & 0.308 & 0.250 & 0.381 & 0.353 & 0.308 \\
\hline UK & 0.542 & $0.667^{*}$ & 0.647 & $0.769 * *$ & 0.625 & 0.619 & 0.647 & $0.769 * *$ \\
\hline Japan & 0.542 & $0.810 * * *$ & $0.882^{* * *}$ & $0.923 * * *$ & 0.583 & $0.810^{* * *}$ & $0.824^{* * *}$ & $1.000 * * *$ \\
\hline Korea & 0.417 & 0.476 & 0.471 & 0.462 & 0.417 & 0.476 & 0.471 & 0.462 \\
\hline Norway & 0.417 & 0.619 & 0.588 & $0.692^{*}$ & 0.333 & 0.619 & 0.647 & 0.615 \\
\hline Sweden & 0.625 & 0.476 & 0.412 & 0.538 & 0.542 & 0.476 & 0.412 & 0.538 \\
\hline Switzerland & 0.583 & $0.667^{*}$ & $0.824 * * *$ & $1.000 * * *$ & 0.542 & $0.667^{*}$ & $0.882^{* * *}$ & $0.923 * * *$ \\
\hline Euro & 0.500 & 0.571 & $0.706^{* *}$ & $0.846^{* * *}$ & 0.500 & 0.429 & 0.294 & 0.154 \\
\hline Direction $>0.5$ & 4 & 5 & 5 & 6 & 4 & 5 & 5 & 5 \\
\hline No. $D M W^{*}$ & 0 & 3 & 3 & 5 & 0 & 2 & 2 & 3 \\
\hline \multicolumn{9}{|c|}{ TRen: Heterogeneous rule without interest rate smoothing } \\
\hline Australia & 0.333 & 0.286 & 0.294 & 0.077 & 0.333 & 0.333 & 0.353 & 0.077 \\
\hline Canada & 0.375 & 0.381 & 0.353 & 0.231 & 0.500 & 0.333 & $0.706^{* *}$ & 0.462 \\
\hline Denmark & 0.375 & 0.381 & 0.471 & 0.462 & 0.583 & 0.619 & 0.529 & 0.385 \\
\hline UK & 0.458 & $0.667^{*}$ & 0.647 & $0.769 * *$ & $0.667^{*}$ & 0.571 & 0.529 & 0.615 \\
\hline Japan & 0.625 & $0.810 * * *$ & $0.882^{* * *}$ & $0.923 * * *$ & 0.583 & $0.810 * * *$ & $0.882^{* * *}$ & $0.846 * * *$ \\
\hline Korea & 0.417 & 0.476 & 0.531 & 0.462 & 0.417 & 0.476 & 0.471 & 0.538 \\
\hline Norway & 0.583 & 0.524 & 0.471 & $0.846 * * *$ & 0.625 & 0.619 & $0.824^{* * *}$ & $0.923 * * *$ \\
\hline Sweden & 0.542 & 0.571 & 0.412 & $0.923^{* * *}$ & 0.542 & 0.476 & 0.412 & 0.538 \\
\hline Switzerland & 0.542 & $0.667^{*}$ & $0.706 * * *$ & $1.000 * * *$ & 0.458 & $0.667^{*}$ & $0.824^{* * *}$ & $0.923 * * *$ \\
\hline Euro & 0.458 & 0.571 & $0.706^{* *}$ & $0.846 * * *$ & 0.500 & 0.429 & 0.294 & 0.154 \\
\hline Direction $>0.5$ & 4 & 6 & 5 & 6 & 5 & 5 & 6 & 6 \\
\hline No. $D M W^{*}$ & 0 & 3 & 3 & 6 & 1 & 2 & 4 & 3 \\
\hline
\end{tabular}

Notes: Proportion of times the TVP forecasting regression and the Fixed-effect (FE) panel regression predict the correct sign of exchange rate change. Values above 0.5 indicate that the fundamentals-based regression is able to predict the direction of exchange rate change, while values below 0.5 suggest that the regression tends to predict the wrong direction of change. The Table also reports the DMW teststatistic for the hypothesis that the predictions of the fundamentals-based model are no better than a naive model that predicts that the exchange rate has an equal chance to go up or down. Asterisks (* $\left.10 \%,{ }^{* *} 5 \%,{ }^{* * *} 1 \%\right)$ denote the level of significance at which this hypothesis is rejected, suggesting that the regression significantly predicts the direction of change in exchange rate. The last two rows at the bottom of the Table show the number of proportions greater than 0.5 ("Direction $>0.5$ ") and the number of rejections of the DMW-test. 
rather than the FE panel regression. As well, these significant cases tend to increase with the forecast horizon, reaching as many as three out of six for the FE panel model and TRen fundamentals at $h=12$; and all the six currencies for which the direction statistic is above 0.5 for the TVP regression at $h=12$ and similar fundamentals.

All in all, we interpret our results as an endorsement of our approach to allow for timeevolving fundamentals, and more generally, time-changing dynamics in the interaction between exchange rates and fundamentals.

\section{Conclusion}

An expanding literature articulates the view that Taylor rules are helpful in predicting exchange rates in the sense that structural exchange rate models incorporating Taylor rule fundamentals exhibit predictive content for exchange rates. See, for example, Engel and West (2005) and Molodtsova and Papell (2009). At the same time, an established literature documents time-evolving macroeconomic conditions and relationships among macroeconomic variables (e.g., Stock and Watson, 1996). Taken together, these observations raise the possibility that accounting for time-evolving dynamics may be fundamental to improve exchange rate models' forecasting ability.

To explore this possibility, we estimate Taylor rule fundamentals with Time Varying Parameters (TVP) models and examine their predictive content for exchange rates in a framework that also allows for the parameters of the forecasting regression to change over time. We focus in three alternative forecast samples and four quarterly forecast horizons. In the more recent parts of our dataset and horizons beyond 1-quarter, our approach yields a lower root mean squared forecast error than the driftless random walk for at least half of the currencies in the sample, reaching as many as seven out of 10. Results are especially strong when the TVP of the Taylor rule are allowed to differ between countries. We interpret this support for heterogeneity as reflecting the varying degree at which country-specific fundamentals altered during the recent financial turmoil.

When we experiment with the usual approach in the literature, whereby constantparameter models are used to compute Taylor rule fundamentals and forecast, we find 
a slightly limited performance in the recent turbulent periods. However, these constant parameter models perform relatively well in the earlier parts of our dataset. When employed in a rolling forecasting approach, they also perform only marginally poor than our TVP forecasting regression. Our results are robust to a number of situations, including to the use of an alternative forecasting approach, to change in the base currency, to using monthly data, to using unemployment gap in the Taylor rules, and to employing the direction of change statistic. Hence, we remain optimistic about the forecasting approach we pursue.

\section{Appendix A. Bayesian estimation of time-varying parameter models}

This Appendix describes the Bayesian approach we pursue to estimate our timevarying parameter (TVP) models. We present the prior hyperparameters, the conditional posterior distributions, and the steps or algorithm used to draw from these conditional distributions. Our exposition draws mainly from Kim and Nelson (1999, Ch. 8) and Blake and Mumtaz (2012, Ch. 3).

Our TVP models have the following general state-space representation:

$$
\begin{array}{ll}
y_{t}=H_{t} \beta_{t}+A z_{t}+e_{t}, & \text { observation equation; } \\
\beta_{t}=\mu+F \beta_{t-1}+v_{t}, & \text { transition equation; }
\end{array}
$$

where $e_{t} \sim$ i.i.d. $(0, R), v_{t} \sim$ i.i.d. $(0, Q)$, and $\operatorname{Cov}\left(e_{t}, v_{t}\right)=0$. Further, $y_{t}$ is an $(n \times 1)$ vector of observations on $n$ variables over time; $\beta_{t}$ is a $(k \times 1)$ vector of unobserved state variables (e.g. the time-varying coefficients); $H_{t}$ is an $(n \times k)$ matrix with elements that are not fixed or given as data; $z_{t}$ is an $(r \times 1)$ vector of exogenous variables with timeinvariant coefficients $A$. In terms of our precise TVP specifications in Sections (2) and $(3), y_{t} \equiv \Delta s_{t}$ and $y_{t} \equiv i_{t}-i_{t}^{*}, H_{t}$ contains the respective explanatory variables, $A z_{t}=0$, $\mu=0$, and $F$ is an identity matrix $\left(I_{k}\right)$, refer to Eq. (1) and Eq. (5) in the main text.

\section{Priors hyperparameters and initial conditions}

The form of our TVP models suggests that we need priors for the variance $R$ of 
the measurement or observation equation and the variance-covariance matrix $Q$ of the transition equation. In addition, to recover the unobserved state variable $\beta_{t}$ we need initial conditions or starting values for the Kalman filter (i.e., the initial state, $\beta_{0 \mid 0}$, and and its initial variance $\left.P_{0 \mid 0}\right)$. See Kim and Nelson $(1999$, Ch. 3) for details about the Kalman filter.

To parameterize the prior distributions and initial conditions we use pre-sample information. Specifically, we use a training sample of $T_{0}=20$ observations to estimate via OLS estimator a fixed-coefficient model which is a counterpart to Eq. (A.1). The estimated coefficients and their corresponding covariance matrix are set as initial conditions for the Kalman filter. In notation:

$$
\begin{aligned}
& \beta_{0 \mid 0} \equiv \beta_{O L S}=\left(H_{0 t}^{\prime} H_{0 t}\right)^{-1}\left(H_{0 t}^{\prime} y_{0 t}\right), \\
& P_{0 \mid 0} \equiv P_{O L S}=\Sigma_{0} \otimes\left(H_{0 t}^{\prime} H_{0 t}\right)^{-1},
\end{aligned}
$$

where $\beta_{O L S}$ and $P_{O L S}$ are, respectively, the coefficients' vector and covariance matrix from an OLS regression, and $\Sigma_{0}=\left(y_{0 t}-H_{0 t} \beta_{0}\right)^{\prime}\left(y_{0 t}-H_{0 t} \beta_{0}\right) /\left(T_{0}-k\right)$.

The prior for $Q$ is inverse Wishart, with $T_{0}$ degrees of freedom and $Q_{0}$ scale matrix, i.e., $P(Q) \sim I W\left(Q_{0}, T_{0}\right)$. This prior influences the amount of time-variation in the coefficients. A large value for the scale matrix $Q_{0}$ is consistent with more fluctuation in the coefficients. We set $Q_{0}=P_{0 \mid 0} \times T_{0} \times \tau$, where $\tau$ is a scaling factor that reflects our beliefs about the preciseness of $P_{0 \mid 0}$. Since our training sample $T_{0}$ is small, we consider that the estimate of $P_{0 \mid 0}$ is very imprecise and set $\tau=3.510^{-6}$ for all models. ${ }^{20}$ This reasoning accords with Blake and Mumtaz (2012, Ch. 3).

The prior for the variance of the measurement equation is $P(R) \sim I G\left(R_{0}, T_{0}-k\right)$, where $R_{0}=\Sigma_{O L S}$ is the scale parameter, and $\left(T_{0}-k\right)$ is the prior degree of freedom. To initialize the first step of the Gibbs sampling we need starting values for $R$ and $Q$. We set them to $R_{0}=\Sigma_{O L S}$ and $Q_{0}=P_{0 \mid 0} \times T_{0} \times \tau$.

\footnotetext{
${ }^{20}$ Note also that the training sample size reduces with the forecast horizon. For example, the size of the training sample used to parameterize the prior for the forecasting regression at 12-quarters-ahead is $T_{0}=20-h$. With two coefficients $(k=2)$ to be estimated we have six degrees of freedom.
} 


\section{Conditional posterior distribution}

In addition to priors and initial conditions our methods necessitate the forms of the conditional posterior distributions. The conditional posterior distributions for the state variable $\left(\widetilde{\beta}_{T}\right)$ given the other parameters of our TVP model is given by:

$$
H\left(\widetilde{\beta}_{T} \mid \widetilde{y}_{T}, R, Q\right)=H\left(\beta_{T} \mid \widetilde{y}_{T}\right) \prod_{t=1}^{T-1} H\left(\beta_{t} \mid \beta_{t+1}, \widetilde{y}_{t}\right),
$$

where $\widetilde{\beta}_{T}=\left[\beta_{1}, \beta_{2}, \ldots, \beta_{T}\right]$ and $\widetilde{y}_{T}=\left[y_{1}, y_{2}, \ldots, y_{T}\right]$. The conditional posterior distribution of $R$ given a draw of the state variable $\beta_{t}$ and the other parameters is given by:

$$
H\left(R \mid \beta_{t}, y_{t}, Q\right) \sim \Gamma^{-1}\left(\frac{T_{0}-k+T}{2}, \frac{\theta_{1}}{2}\right)
$$

where $\theta_{1}=R_{0}+\left(y_{t}-\beta_{t} H\right)^{\prime}\left(y_{t}-\beta_{t} H\right)$. The conditional posterior distribution of $Q$ given a draw of the state variable $\beta_{t}$ and the other parameters is:

$$
H\left(Q \mid \beta_{t}, y_{t}, R\right) \sim I W\left(\bar{Q}, T+T_{0}\right)
$$

where $\bar{Q}=Q_{0}+\left(\beta_{t}-\beta_{t-1}\right)^{\prime}\left(\beta_{t}-\beta_{t-1}\right)$.

\section{Sampling from the conditional posterior distribution}

To draw samples from the conditional posterior distributions we use the Carter and Kohn (1994) algorithm with the Gibbs sampler. The Carter and Kohn algorithm provide us with the draws of the state variable $\widetilde{\beta}_{T}=\left[\beta_{1}, \beta_{2}, \ldots, \beta_{T}\right]$ from its conditional posterior distribution. The key updating equations are:

$$
\begin{aligned}
& \beta_{t \mid t, \beta_{t+1}}=\beta_{t \mid t}+K^{*} \times\left(\beta_{t+1}-\mu+F \beta_{t \mid t}\right), \\
& P_{t \mid t, \beta_{t+1}}=P_{t \mid t}-K^{*} \times H^{*} \times P_{t \mid t}
\end{aligned}
$$

where $\beta_{t \mid t}$ and $P_{t \mid t}$ are obtained from the Kalman filter and $K^{*}=P_{t \mid t} \times H^{*^{\prime}} \times f_{t+1 \mid t}^{-1}$. Equations (A.8) and (A.9) are substituted backwards from $T-1$, and iterating backwards 
to period 1. In fact, this step is an integral part of the Gibbs sampling algorithm which proceeds as follows: ${ }^{21}$

- Step 1: Conditional on $R$ and $Q$, draw $\beta_{t}$ from its conditional posterior distribution given in (A.5) using the Kalman filter and the Carter and Kohn algorithm.

- Step 2: Conditional on $\beta_{t}$, sample $R$ from its conditional posterior distributions given in Expression (A.6).

- Step 3: Conditional on $\beta_{t}$, sample $Q$ from its conditional posterior distribution given by the expression (A.7).

- Step 4: Repeat steps 1 to 3 a sufficient number of times until convergence is detected.

In our empirical work we use Geweke's convergence test and the relative numerical efficiency measure to assess the convergence of the algorithm, and find that 1700 draws are sufficient. We then discard the first 300 draws and save the last 1400 draws for inference. We then use the mean of the marginal posterior distribution of $\beta_{t}$, as the coefficient's point estimate.

\section{Aknowledgements}

We are grateful to Charles Engel, Kenneth D. West, an anonymous reviewer, and participants at the 2014 International Association for Applied Econometrics (IAAE) Conference, for helpful comments. Ribeiro acknowledges financial support from the IAAE.

\section{References}

[1] Bacchetta, P. and van Wincoop, E. (2004). A scapegoat model of exchange-rate fluctuations. American Economic Review, 94(2):114-118.

[2] Bacchetta, P., Wincoop, E. v., and Beutler, T. (2009). Can parameter instability explain the Meese-Rogoff puzzle? NBER International Seminar on Macroeconomics, $6(1): 125-173$.

\footnotetext{
${ }^{21}$ See Blake and Mumtaz (2012, Ch. 3) for a textbook explanation.
} 
[3] Balke, N. S., Ma, J., and Wohar, M. E. (2013). The contribution of economic fundamentals to movements in exchange rates. Journal of International Economics, 90(1):116.

[4] Blake, A. P. and Mumtaz, H. (2012). Applied Bayesian econometrics for central bankers. Number 4 in Technical Handbook. Centre for Central Banking Studies, Bank of England, London.

[5] Boivin, J. (2006). Has US monetary policy changed? Evidence from drifting coefficients and real-time data. Journal of Money, Credit and Banking, 38(5):1149-1173.

[6] Carter, C. K. and Kohn, R. (1994). On Gibbs sampling for state space models. Biometrika, 81(3):541-553.

[7] Chen, Y.-C., Rogoff, K. S., and Rossi, B. (2010). Can exchange rates forecast commodity prices? The Quarterly Journal of Economics, 125(3):1145-1194.

[8] Cheung, Y.-W., Chinn, M. D., and Pascual, A. G. (2005). Empirical exchange rate models of the nineties: Are any fit to survive? Journal of International Money and Finance, 24(7):1150-1175.

[9] Clark, T. E. and West, K. D. (2006). Using out-of-sample mean squared prediction errors to test the martingale difference hypothesis. Journal of Econometrics, 135(1):155-186.

[10] Cogley, T., Primiceri, G. E., and Sargent, T. J. (2010). Inflation-gap persistence in the US. American Economic Journal: Macroeconomics, 2(1):43-69.

[11] Diebold, F. X. and Mariano, R. S. (1995). Comparing predictive accuracy. Journal of Business and Economic Statistics, 13(3):253-63.

[12] Draghi, M. (2014). Monetary policy communication in turbulent times. In Conference De Nederlandsche Bank 200 years: Central banking in the next two decades. European Central Bank. 
[13] Engel, C. (1996). The forward discount anomaly and the risk premium: A survey of recent evidence. Journal of Empirical Finance, 3(2):123-192.

[14] Engel, C., Mark, N. C., and West, K. D. (2008). Exchange rate models are not as bad as you think. In Daron Acemoglu, K. R. and Woodford, M., editors, NBER Macroeconomics Annual 2007, volume 22, pages 381-473. University of Chicago Press.

[15] Engel, C., Mark, N. C., and West, K. D. (2015). Factor model forecasts of exchange rates. Econometric Reviews, 34(1-2):32-55.

[16] Engel, C. and West, K. D. (2004). Accounting for exchange-rate variability in present-value models when the discount factor is near one. American Economic Review, $94(2): 119-125$.

[17] Engel, C. and West, K. D. (2005). Exchange rates and fundamentals. Journal of Political Economy, 113(3):485-517.

[18] Engel, C. and West, K. D. (2006). Taylor rules and the Deutschmark-Dollar real exchange rate. Journal of Money, Credit and Banking, 38(5):1175-1194.

[19] Giannone, D. (2009). Comment on "Can parameter instability explain the MeeseRogoff puzzle?". NBER International Seminar on Macroeconomics, 6(1):180-190.

[20] Gourinchas, P.-O. and Tornell, A. (2004). Exchange rate puzzles and distorted beliefs. Journal of International Economics, 64(2):303 - 333.

[21] Hodrick, R. J. and Prescott, E. C. (1997). Postwar US business cycles: An empirical investigation. Journal of Money, Credit and Banking, 29(1):1-16.

[22] Ince, O. (2014). Forecasting exchange rates out-of-sample with panel methods and real-time data. Journal of International Money and Finance, 43:1-18.

[23] Kilian, L. (1999). Exchange rates and monetary fundamentals: What do we learn from long-horizon regressions? Journal of Applied Econometrics, 14(5):491-510. 
[24] Kilian, L. and Taylor, M. P. (2003). Why is it so difficult to beat the random walk forecast of exchange rates? Journal of International Economics, 60(1):85-107.

[25] Kim, C.-J. and Nelson, C. R. (1999). State-space models with regime switching: Classical and Gibbs-sampling approaches with applications. The MIT Press, London.

[26] Kim, C.-J. and Nelson, C. R. (2006). Estimation of a forward-looking monetary policy rule: A time-varying parameter model using ex post data. Journal of Monetary Economics, 53(8):1949-1966.

[27] Korobilis, D. (2013). VAR forecasting using Bayesian variable selection. Journal of Applied Econometrics, 28(2):204-230.

[28] Mark, N. C. (1995). Exchange rates and fundamentals: Evidence on long-horizon predictability. The American Economic Review, 85(1):201-218.

[29] Mark, N. C. (2009). Changing monetary policy rules, learning, and real exchange rate dynamics. Journal of Money, Credit and Banking, 41(6):1047-1070.

[30] Meese, R. A. and Rogoff, K. (1983). Empirical exchange rate models of the seventies: Do they fit out of sample? Journal of International Economics, 14(1):3-24.

[31] Molodtsova, T. and Papell, D. H. (2009). Out-of-sample exchange rate predictability with Taylor rule fundamentals. Journal of International Economics, 77(2):167-180.

[32] Molodtsova, T. and Papell, D. H. (2013). Taylor rule exchange rate forecasting during the financial crisis. NBER International Seminar on Macroeconomics, 9(1):55-97.

[33] Mumtaz, H. and Sunder-Plassmann, L. (2013). Time-varying dynamics of the real exchange rate: An empirical analysis. Journal of Applied Econometrics, 28(3):498-525.

[34] Newey, W. K. and West, K. D. (1987). A simple, positive semi-definite, heteroskedasticity and autocorrelation consistent covariance matrix. Econometrica, 55(3):703-08.

[35] Park, C. and Park, S. (2013). Exchange rate predictability and a monetary model with time-varying cointegration coefficients. Journal of International Money and Finance, $37: 394-410$. 
[36] Rogoff, K. S. and Stavrakeva, V. (2008). The continuing puzzle of short horizon exchange rate forecasting. NBER Working Paper 14071, National Bureau of Economic Research.

[37] Rossi, B. (2006). Are exchange rates really random walks? Some evidence robust to parameter instability. Macroeconomic Dynamics, 10(1):20-38.

[38] Rossi, B. (2013). Exchange rate predictability. Journal of Economic Literature, 51(4):1063-1119.

[39] Rossi, B. and Sekhposyan, T. (2011). Understanding models forecasting performance. Journal of Econometrics, 164(1):158-172.

[40] Stock, J. H. and Watson, M. W. (1996). Evidence on structural instability in macroeconomic time series relations. Journal of Business and Economic Statistics, 14(1):1130.

[41] Taylor, J. B. (1993). Discretion versus policy rules in practice. Carnegie-Rochester Conference Series on Public Policy, 39:195-214.

[42] Taylor, J. B. (2009). The financial crisis and the policy responses: An empirical analysis of what went wrong. NBER Working Paper 14631, National Bureau of Economic Research.

[43] Trecroci, C. and Vassalli, M. (2010). Monetary policy regime shifts: New evidence from time-varying interest rate rules. Economic Inquiry, 48(4):933-950.

[44] Watson, M. W. (2007). How accurate are real-time estimates of output trends and gaps? Economic Quarterly, 93(2):143-161.

[45] West, K. D. (1996). Asymptotic inference about predictive ability. Econometrica, 64(5):1067-1084.

[46] Wolff, C. C. (1987). Time-varying parameters and the out-of-sample forecasting performance of structural exchange rate models. Journal of Business and Economic Statistics, 5(1):87-97. 